\title{
The nodal dependence of long-period ocean tides in the Drake Passage
}

\author{
Philip L. Woodworth and Angela Hibbert \\ National Oceanography Centre, Joseph Proudman Building, 6 Brownlow Street, Liverpool, L3 5DA, UK
}

Correspondence: Philip L. Woodworth (plw@ noc.ac.uk)

Received: 16 April 2018 - Discussion started: 23 April 2018

Revised: 26 June 2018 - Accepted: 27 June 2018 - Published: 26 July 2018

\begin{abstract}
Almost three decades of bottom pressure recorder (BPR) measurements at the Drake Passage, and 31 years of hourly tide gauge data from the Vernadsky Research Base on the Antarctic Peninsula, have been used to investigate the temporal and spatial variations in this region of the three main long-period tides Mf, Mm and Mt (in order of decreasing amplitude, with periods of a fortnight, a month and one-third of a month, respectively). The amplitudes of Mf and Mt, and the phase lags for all three constituents, vary over the nodal cycle (18.61 years) in essentially the same way as in the equilibrium tide, so confirming the validity of Doodson's "nodal factors" for these constituents. The amplitude of Mm is found to be essentially constant, and so inconsistent at the $3 \sigma$ level from the $\pm 13 \%$ (or $\sim \pm 0.15$ mbar) anticipated variation over the nodal cycle, which can probably be explained by energetic non-tidal variability in the records at monthly timescales and longer. The north-south differences in amplitude for all three constituents are consistent with those in a modern ocean tide model (FES2014), as are those in phase lag for Mf and Mt, while the phase difference for Mm is smaller than in the model. BPR measurements are shown to be considerably superior to coastal tide gauge data in such studies, due to the larger proportion of non-tidal variability in the latter. However, correction of the tide gauge records for non-tidal variability results in the uncertainties in nodal parameters being reduced by a factor of 2 (for Mf at least) to a magnitude comparable (approximately twice) to those obtained from the BPR data.
\end{abstract}

\section{Introduction}

The ocean tide at each location is usually represented as a combination of harmonic constituents with frequencies corresponding to those of lines in the tidal potential (Cartwright and Tayler, 1971; Cartwright and Edden, 1973). The major lunar constituents are always accompanied by sidebands separated in frequency by $\pm 1 / 18.61$ cycles per year, 18.61 years being the nodal (or draconic) period of regression in the mean longitude of the lunar ascending node (Doodson and Warburg, 1941). The most efficient way of accounting for the sidebands in a harmonic expansion is via the use of "nodal factors" $f$ and $u$, whereby the simple representation of a single constituent,

$H \cos (\omega t+A-G)$

in which $\omega$ is the angular frequency of the constituent, $H$ and $G$ are its amplitude and phase lag, and $A$ is its astronomical argument at time $t=0$, is modified to

$f H \cos (\omega t+A+u-G)$,

where $f$ and $u$ are time-dependent functions of the longitude of the ascending node $(N)$. For example, in the tidal potential (or equilibrium tide), the main lunar semi-diurnal tide (M2) has nodal factors:

$f=1.0-0.037 \cos (N), u=-2.1^{\circ} \sin (N)$,

retaining only terms in $\cos (N)$ and $\sin (N)$, and neglecting smaller terms depending on $\cos (2 N)$, and so on (Doodson, 1928; Doodson and Warburg, 1941; Pugh and Woodworth, 2014).

Because the frequencies of the sidebands are similar to the constituent's central frequency, it is usually assumed that the 
response of the ocean at the sidebands and at the central frequency will be in proportion to that given in the tidal potential, i.e. that the same admittance will apply. However, nodal factors different from expectations from the tidal potential (or equilibrium tide) have been found at many locations, at least for semi-diurnal tides.

For example, smaller values of $f$ for M2 were found around the UK by Amin $(1983,1985)$ and were explained as being a consequence of non-linear frictional damping. Similar findings were obtained from measurements of mean tidal range around the UK by Woodworth et al. (1991). Differences from the expected nodal factors were found in data from the west coast of Australia (Amin, 1993) and the Bay of Fundy and Gulf of Maine (Ku et al., 1985; Ray, 2006; Müller, 2011). Feng et al. (2015) found differences for both semi-diurnal and diurnal tides at locations along the coast of China. In a survey of long-term changes in the amplitudes and phase lags of the four main tidal constituents around the world (M2, S2, O1 and K1), Woodworth (2010) pointed to many locations where differences in $f$ from those expected from the equilibrium tide were evident.

Turning to the long-period tides, all of the long-period constituents of the equilibrium tide have amplitudes proportional to $\left(\frac{1}{3}-\sin ^{2}\right.$ (latitude) $)$ with no zonal dependence. The amplitudes are twice as large at the poles as at the Equator, they are $180^{\circ}$ out of phase between high and low latitudes, and they have zero amplitude at $35^{\circ} \mathrm{N} / \mathrm{S}$. Proudman (1960) suggested that, at least for the longest of the long-period tides (the 18.61-year nodal tide), the tide in the real ocean should be a close approximation of its equilibrium form, and that still seems to be a good theory (Woodworth, 2012). However, tidal modelling and observations by tide gauges and satellite altimetry have demonstrated that the long-period tides with shorter periods in the real ocean, such as Mf and Mm with periods of approximately a fortnight and a month, respectively, have significant spatial variations from their equilibrium form (Wunsch et al., 1997; Mathers and Woodworth, 2001; Egbert and Ray, 2003; Lyard et al., 2006; Ray and Egbert, 2012; Ray and Erofeeva, 2014).

Although the spatial variations of the long-period tides are now much better understood, it is also of interest to consider whether their temporal (nodal) variability conforms to expectations. The Mf constituent (period of 13.66 days) is particularly interesting in this regard. In the equilibrium tide, $\mathrm{Mf}$ is the largest of the long-period tides and has very large nodal variations:

$f=1.043+0.414 \cos (N), u=-23.7^{\circ} \sin (N)$

(Doodson and Warburg, 1941). Why the first term in $f$ is not identically 1.0 (for Mf and for many other constituents) arises from the way that Doodson (1928) combined sideband constituents in order to provide simple functions in terms of $N$ only. Doodson's nodal parameterisations, especially those for Mf, are discussed in the Appendix.
As far as we know, the magnitude of this temporal variability for the long-period tides in the real ocean has never been verified properly. In principle, one would have expected that the relatively large amplitude and short period of Mf would have enabled the temporal variation of its amplitude and phase lag to be estimated reliably from two decades of tide gauge data. However, there is always non-tidal background variability at fortnightly timescales to contend with. Most research on long-period tides in tide gauge records has been focused on regions such as the low-latitude Pacific, where the non-tidal background variability is much lower than at higher latitudes (e.g. Miller et al., 1993). However, the longperiod tides are also small in these regions (i.e. centimetric; see Fig. 5 of Ray and Egbert, 2012). These studies of Pacific data were primarily concerned with establishing how the non-equilibrium aspects of Mf and Mm varied spatially, rather than temporally (Wunsch, 1967). Even though some long tide gauge records exist at high latitudes (e.g. northern Norway or Canada), where long-period amplitudes are larger, the relatively high background of non-tidal sea level variability means that it is difficult to make an accurate determination of the long-period tides without also modelling the non-tidal background (e.g. Crawford, 1982).

In this paper, we report on the temporal variations of the amplitudes and phase lags of Mf, Mm and Mt (period of one-third of a month) at the Drake Passage to see if they are consistent with equilibrium expectations. These are the three long-period tides, in order of decreasing amplitude in the equilibrium tide, that one is likely to be able to extract from records of about 1 year. The Drake Passage is at a sufficiently high latitude that any long-period tides should be larger than in most parts of the ocean. In addition, our investigation is based on the use of measurements of bottom pressure (BP) obtained over almost three decades, instead of on conventional coastal tide gauge data. It will be seen that bottom pressure recorders (BPRs) are inherently more suitable for providing long-period tidal information than coastal tide gauges. However, as a comparison of different measurement techniques, we also make use of 31 years of hourly sea level data from the nearby Vernadsky Research Base, which has the longest tide gauge record in Antarctica.

\section{Bottom pressure recorder data and methods}

Cartwright (1999, chap. 13) provides a history of the development of BPRs, primarily by groups in Germany, France, USA and UK. Cartwright himself and colleagues from the National Oceanography Centre (NOC, as it is now called) made extensive use of BPRs in sets of "pelagic" (pertaining to the open sea) tidal measurements, first in waters around the UK, and then throughout the Atlantic Ocean (Cartwright et al., 1988; Spencer and Vassie, 1997). The same equipment was also used in international studies of non-tidal ocean processes (e.g. Cartwright et al., 1987), culminating in the 
late 1980s in the deployment of BPRs at the Drake Passage in order to monitor fluctuations in the transport of the Antarctic Circumpolar Current (ACC) as part of the World Ocean Circulation Experiment (Woodworth et al., 2002).

Most of the BPR deployments were made on the north and south sides of the Drake Passage in order to measure changes in the pressure gradient between them. Bottom landers based on the "Mk.IV" or similar designs were used in most cases (Fig. 1a, Spencer and Vassie, 1997). Over half of the deployments took the form of recoveries and redeployments on an annual basis at depths around $1000 \mathrm{~m}$, providing records of $15 \mathrm{~min}$ average bottom pressure typically 1 year long. The other half of the deployments were made at greater depths, between 2000 and $4000 \mathrm{~m}$. Three deployments were made using the longer-duration Multi-Year Return Time Level Equipment (MYRTLE) instrument that provided BP records approximately 4 years long (Fig. 1b). The measurement programme was terminated in 2016, resulting in a BP data set spanning almost three decades.

The measurements have been used in studies of ACC variability, as reviewed by Meredith et al. (2011). BP measured at the south side of the Drake Passage has been shown to be particularly useful as a monitor of fluctuations in ACC transport (Hughes et al., 2003; Hibbert et al., 2010). The data have even proved to be useful in studies of tsunami travel times (Rabinovich et al., 2011). In regard to tides, the data have been employed in validation studies of models of the semi-diurnal and diurnal tides observed by satellite altimetry (Ray, 2013).

BP has advantages in tidal studies over sea level recorded by conventional tide gauges at the coast. An obvious factor is that BPRs can be deployed in deep water offshore (pelagic), at some distance from where storm surges and other shallowwater processes are largest. Another factor is that much of the sea level variability due to air pressure changes is compensated automatically by air pressure itself in the bottom pressure measurement (the inverse barometer effect). As a result of these two factors, BP records tend to have a smaller percentage of non-tidal variability (or "noise") than do tide gauge records.

The main disadvantages of a BP record are instrumental drift (also known as "creep") and the absence of a geodetic datum. Fortunately for tidal studies, creep is a slow, monotonic process that tends not to impact upon the determination of high-frequency components of the record, such as the semi-diurnal and diurnal tides (Watts and Kontoyiannis, 1990; Spencer and Vassie, 1997; Polster et al., 2009). Instrumental drift does tend to preclude the reliable observation of annual and semi-annual tides in BPR data. However, these long-period tides are not of lunar origin and so are not the concern of the present investigation. The absence of a datum is an important factor when it is required to combine individual yearly records into longer, continuous records. Unless overlapping records are available, from which the datum of one deployment can be related to that of another, then tech- niques such as "end-point matching" have to be employed (e.g. Meredith et al., 2004). Although we make use of one such combined record below, in order to demonstrate clearly the existence of long-period tides in the data, combinations of records are not required for most of the present study in which we analyse the records from each deployment separately.

Almost all the Drake Passage BPR data obtained by NOC since 1992 have been reanalysed recently as part of a Natural Environment Research Council (NERC) project called "Weighing the Ocean". (Several NOC deployments in the centre of the Drake Passage and in the Scotia Sea were not included.) Data were subjected to a new set of quality control that identified any suspect measurements and corrected as far as possible for timing uncertainties and instrumental drift. The processed data, consisting of records from 35 individual deployments, are available on the website of the Permanent Service for Mean Sea Level (PSMSL) (http://www.psmsl.org, last access: 1 June 2018). A total of 10 other records were added from deployments before 1992 at the Drake Passage and from the Falkland-Signy (F-S) line (Woodworth et al., 1996). These earlier records can be obtained from http://www.ntslf.org/files/acclaimdata/bprs/ (last access: 1 June 2018).

Figure 2 shows the locations of the 45 deployments, many of which were at essentially the same positions and so overlap on the map. The 35 locations with reanalysed data from the PSMSL website include those on the north and south sides of the Drake Passage south of the Falkland Islands, and that of the first of the three MYRTLE deployments close to Signy Island. The two other MYRTLE deployments were also made on the south side but in more central positions. The 10 earlier deployments include the westernmost north-south pair and those on the $\mathrm{F}-\mathrm{S}$ line to the east.

We have treated the data from each deployment as separate records, with record lengths from 296 to 1470 days. Each record of BP was first subjected to a tidal analysis consisting of typically 57 semi-diurnal, diurnal and higherfrequency constituents, the exact number of constituents depending on the record length. However, importantly, longperiod tides were not included in the tidal analysis. Residuals of the analysis were interpolated to hourly values, and simple arithmetic averaging of the 24-hourly residuals each day provided the time series of daily mean values of BP that are discussed below. For full details of the data processing, see http://www.psmsl.org/data/bottom_pressure/processing procedures.php (last access: 1 June 2018).

The evidence for long-period tides in the BP data is demonstrated clearly in Fig. 3a. In this case, the individual time series of daily mean BP were de-meaned and de-trended and, when daily values were available from more than one location on the same day (i.e. from both north and south sides of the Drake Passage), they were averaged, so providing a continuous, composite time series spanning over 26 years. Figure $3 \mathrm{a}$ shows the resulting power spectrum which indi- 


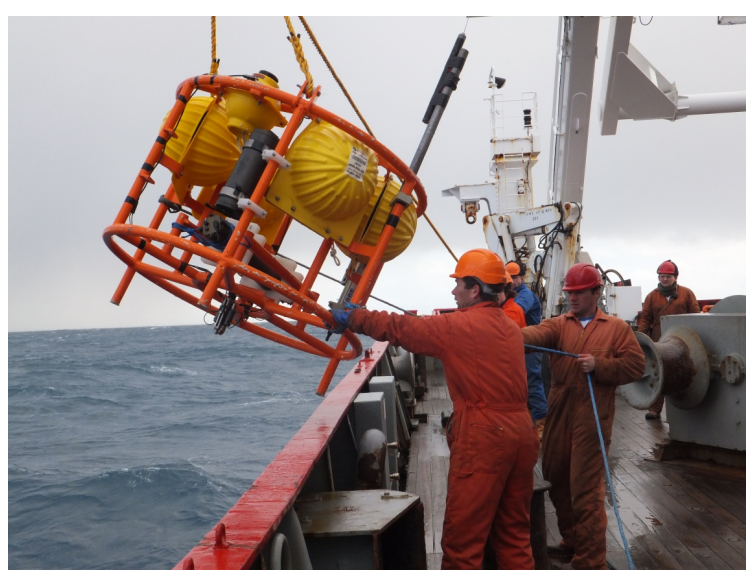

(a)

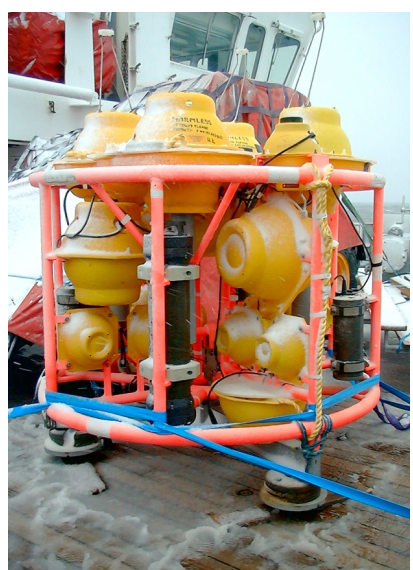

(b)

Figure 1. (a) The "Mk.IV" and (b) MYRTLE bottom pressure recorders used in the Drake Passage. Panel (a) shows the lander being recovered. Therefore, it is without its heavy ballast frame on which the orange lander frame sits when deployed on the sea bed. A ballast frame can be seen in panel (b). Pressure transducers are installed in the horizontal logger tube in panel (a) and vertical tube in panel (b). Photographs are from the National Oceanography Centre.

cates clearly the presence of Mm (period of 27.55 days), MSf (14.77 days), Mf (13.66 days) and Mt (9.13 days). Such tidal signals are obviously less well resolved when analysing records individually (Fig. 3b). In this case, we are dealing with records of different lengths, at times when the relative proportions of each long-period component (primarily Mf) will be different and when there will be different proportions of tidal and non-tidal variability. Consequently, spectra were produced for each individual record, normalised to have unit energy in the long-period tidal band $(0.02-0.15 \mathrm{cpd})$ and then averaged into bins of $0.005 \mathrm{cpd}$, thus providing a spectrum "typical" of an individual record. It can be seen that Mf, and to a lesser extent $\mathrm{Mm}$, are still present, while Mt is less well resolved, and MSf cannot be seen above the background.

MSf is an interesting constituent that occurs for two reasons. It is partly a long-period tide in its own right, with an amplitude in the equilibrium tide $8.7 \%$ that of Mf, and with variations in amplitude through the nodal cycle of $\pm 14 \%$. It is also partly an interaction constituent (see below), with a nodal variation of $\pm 3.7 \%$ as for M2 in Eq. (3). However, its generally low amplitude suggests that verification of its nodal variation in real data will be much harder than for Mf, $\mathrm{Mm}$ and $\mathrm{Mt}$, and we have not considered MSf in detail further.

In order to study the time dependence of the long-period tides, their amplitudes and phase lags were determined for each deployment record independently by means of a regression of the daily means of BP in terms of three harmonics with periods of Mf, Mm and Mt plus a linear trend. The three periods are so different that the amplitudes and phase lags determined for each harmonic are almost the same whether the regression includes all three constituents or each one individ-

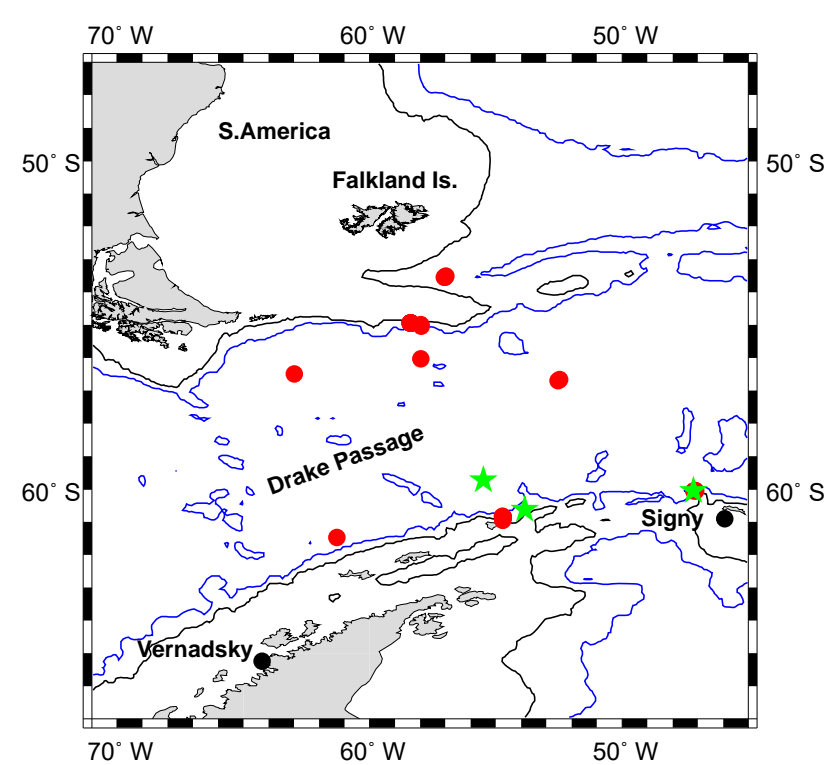

Figure 2. Map of the Drake Passage showing the locations of the 45 BPR deployments and the Vernadsky (Faraday) Research Base. Red dots indicate deployments by bottom landers based on the "Mk.IV" design, while green stars indicate deployments by MYRTLE instruments. Depths of 1000 and $3000 \mathrm{~m}$ are shown by the black and blue contours, respectively.

ually. This procedure assumes that the amplitudes and phase lags of each harmonic do not change during the record, i.e. 


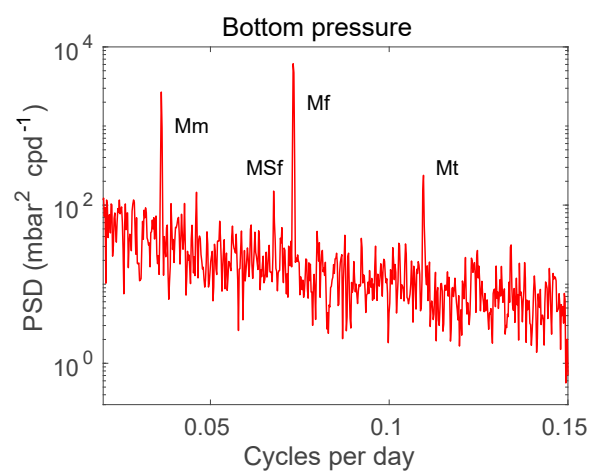

(a)

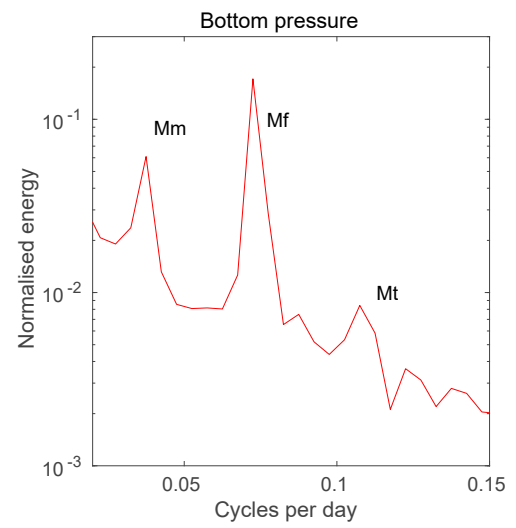

(b)
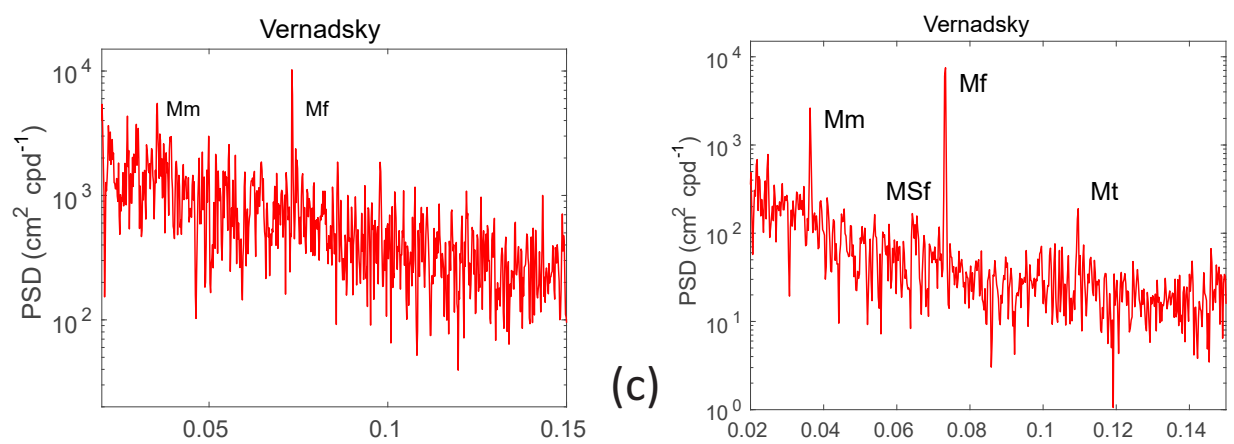

Figure 3. (a) Power spectral density (PSD) between 0.02 and 0.15 cpd of a composite, continuous record of daily mean BP in the Drake Passage spanning over 26 years. (b) An averaged, normalised power spectrum typical of each record made from 20 of the 45 BPR time series which had no data gaps for which the standard deviation of the regression fit in terms of three harmonics was at least $50 \%$ of that of the times series itself, so ensuring a significant tidal component (also see text). (c) PSD of a record of daily mean sea level at Vernadsky Research Base spanning 1984-2014. Panel (d) is the same as (c) but for a shorter record (1993-2014) and following dynamic atmospheric correction (DAC) corrections.

$h(t)=H_{i} \cos \left(\omega t-\varphi_{i}\right)$,

where $h(t)$ is BP for a particular harmonic that is a function of time $t$ measured from the start of $1988, \omega=\left(\frac{2 \pi}{\text { period }}\right)$ radians per day, and $H_{i}$ and $\varphi_{i}$ are the amplitude and phase lag from the regression for deployment $i$. Therefore, one can investigate how $H_{i}$ varies as a function of the central date of each record $\left(T_{i}\right)$, and similarly from Eqs. (2) and (5) one can relate

$\varphi_{i}+A=G-u_{i}$,

where the variation of $\varphi_{i}$ as a function of $T_{i}$ can be described by an oscillation $\left(u_{i}\right)$ around the average phase lag $(G) . A$ is the astronomical argument for the harmonic constituent concerned at the start of 1988. If the start of that year is defined by GMT (UT), then $G$ will be the constituent's Greenwich phase lag.

The regression is made using the G02CGF function of the Numerical Algorithms Group (NAG) library (https://www. nag.co.uk, last access: 1 June 2018). This results in the determined amplitudes for the three harmonics having the same standard errors, while standard errors on each phase lag are defined by the standard error on the amplitude divided by the amplitude itself (times $360^{\circ} / 2 \pi$ ). The same standard error for each amplitude arises from an assumption of white noise in the residuals of the regression. Consequently, they may be potentially estimated too low (see below). However, the magnitude of scatter of the points relative to the nodal fits in Figs. 5-8, compared to their individual formal errors, suggests that the standard errors will have been estimated fairly reliably.

\section{Results for Mf, Mm and Mt}

\subsection{BPR data}

In this section, we discuss findings for Mf, Mm and Mt obtained from the BPR data. Figure 4a shows an example of one of the records of daily mean $\mathrm{BP}$ and the result of a regression fit in terms of the three harmonics. In fact, this is a particularly good example of a record from the north side of the Drake Passage with a relatively small proportion of nontidal variability, at a time (2008-2009) when the amplitude of Mf was larger than average. It serves to make the point 


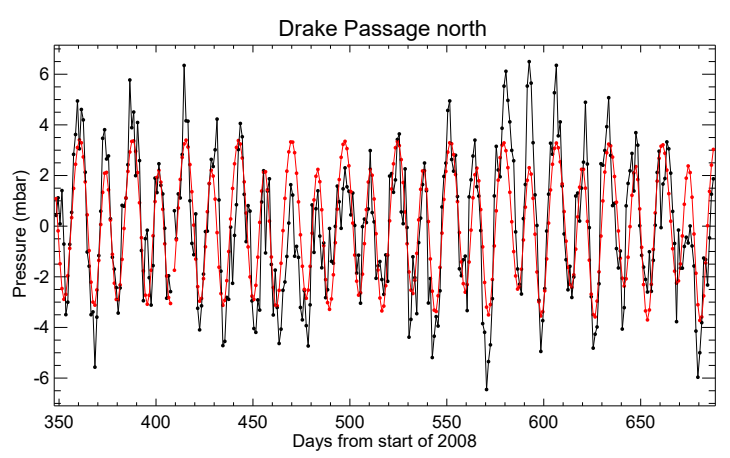

(a)

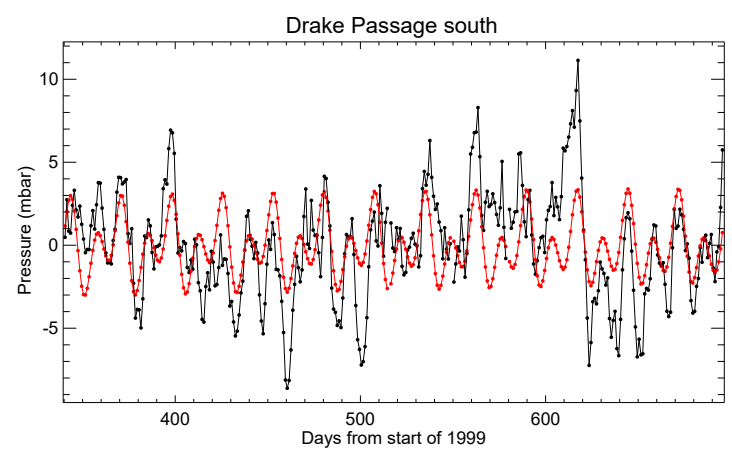

(b)

Figure 4. (a) An example of a fit (red) to daily mean BP values from the north side of the Drake Passage (black) in terms of three harmonics with the frequencies of Mf, Mm and Mt during a period when the amplitude of Mf was larger than average. (b) An example of a record from the south side of the Drake Passage during a period when the amplitude of Mf was smaller than average and so the contribution of $\mathrm{Mm}$ is more apparent.

that information on the amplitude and phase lag of Mf can be extracted reliably from such records.

Figure 2 shows that the deployments in the Drake Passage took place over a large area. However, we can take advantage of the fact that the spatial scale of variation in Mf, and of other long-period tides, is also large (e.g. see Fig. 5 of Ray and Egbert, 2012 and the discussion of the FES2014 model in Sect. 4). Consequently, as a first approximation, all of the values of $H_{i}$ and $G_{i}$ from the many deployments can be considered as having been obtained at the same location.

Figure $5 \mathrm{a}$ and $\mathrm{b}$ present the amplitude and phase lag of Mf, respectively, obtained from the harmonic analysis of each record. The amplitude units are mbar which can be taken as being approximately equivalent to a centimetre of seawater. A clear nodal (18.61-year) variation can be seen in the amplitudes (Fig. 5a), with the red line showing a fit in terms of $\cos (N)$, constrained to peak when $N=0$ at 2006.5. The red line passes equally well through the black and blue points, representing deployments on the north and south sides of the Drake Passage, respectively.

The mean amplitude in the fit is $2.18 \pm 0.04 \mathrm{mbar}$, and the amplitude of the nodal variation is $0.93 \pm 0.06$ mbar, or
$43 \pm 3 \%$ of the mean value, with the sign expected from Eq. (4). This may be compared to the $40 \%$ expected from the equilibrium tide (i.e. $0.414 / 1.043$ in Eq. 4). These and other findings reported below are summarised in Table 1.

If the real Mf had a spatial variation similar to its counterpart in the equilibrium tide, one could adjust the measured amplitudes for the difference in latitude of the various deployments (an equilibrium long-period tide has no variation zonally). Consequently, if the amplitudes in Fig. 5a are multiplied by

$\left(\frac{1}{3}-\sin ^{2}\right.$ (reference latitude) $) /\left(\frac{1}{3}-\sin ^{2}\right.$ (latitude) $)$,

where a reference latitude of $58^{\circ} \mathrm{S}$ is chosen in the middle of the Drake Passage, then one obtains Fig. S1 in the Supplement. There is a larger scatter about the fit than in Fig. 5a, with a $\chi^{2} 3$ times as large. Most of the north-side values (black) are now systematically larger than the south-side values (blue), a result which is inconsistent with Mf amplitudes having the same latitude dependence as in the equilibrium tide.

Figure $5 \mathrm{~b}$ shows the variation in phase lag obtained from each record, i.e. the variation in values of $\left(\varphi_{i}+A\right)$ or $\left(G-u_{i}\right)$. The red line shows a fit in terms of $\sin (N)$, with the nodal variation constrained to be $0^{\circ}$ when $N=0$. The mean value in the fit is $191.9 \pm 1.0^{\circ}$, while the amplitude of the sinusoidal variation is $28.4 \pm 1.4^{\circ}$, which is a little larger than equilibrium tide expectations (Eq. 4). The black and blue points are clearly separated, indicating a phase lag on the south side of the Drake Passage $22 \pm 2^{\circ}$ larger than on the north side (obtained by weighting the individual observed phase lags minus the fitted phase lag by the reciprocal of the square of the standard error on the phase lag). Once again, this is inconsistent with the equilibrium tide, in which both sets would have a phase lag of $180^{\circ}$ at these latitudes.

The next largest long-period tide one can investigate is $\mathrm{Mm}$. This represents more of a challenge, with a longer period (27.55 days) and an amplitude in the equilibrium tide that is approximately half that of Mf. In addition, it has a nodal variation in its equilibrium amplitude that is about a third that of Mf:

$f=1.0-0.130 \cos (N), u=0.0$

(Doodson and Warburg, 1941). Figure 4b shows an example of a BP record from the south side of the Drake Passage, at a time (1999-2000) when the amplitude of Mf was much lower than in Fig. 4a, indicating that Mm can be readily identified by eye at such times. Therefore, we can have some confidence in the harmonic fitting. (To be clear, Fig. 4a and b are not to be taken as examples of north-south differences, rather than differences in the relative proportions of tidal and nontidal variability in all BP time series at different epochs.)

Figure 6a shows the observed variation in $\mathrm{Mm}$ amplitude with no obvious differences between north- and south-side 
(a)

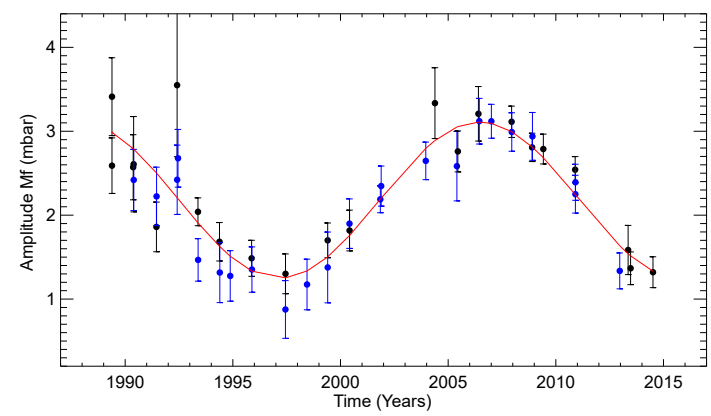

(c)

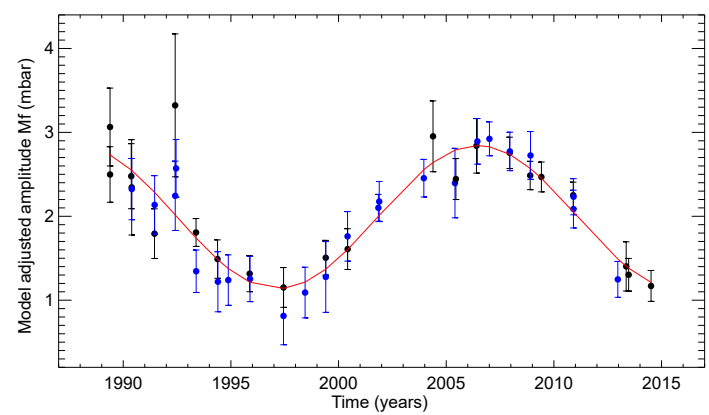

(b)

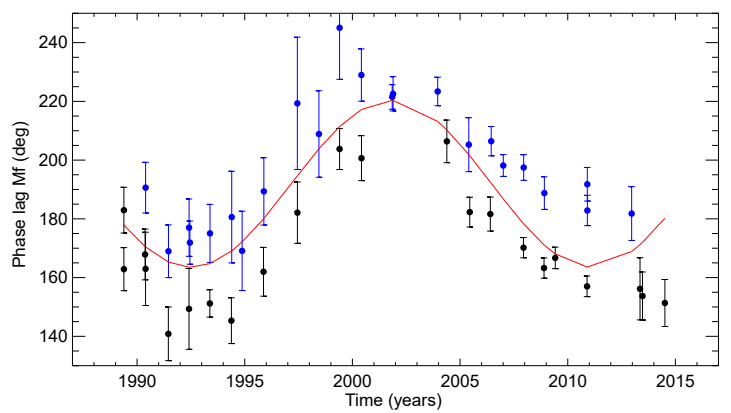

(d)

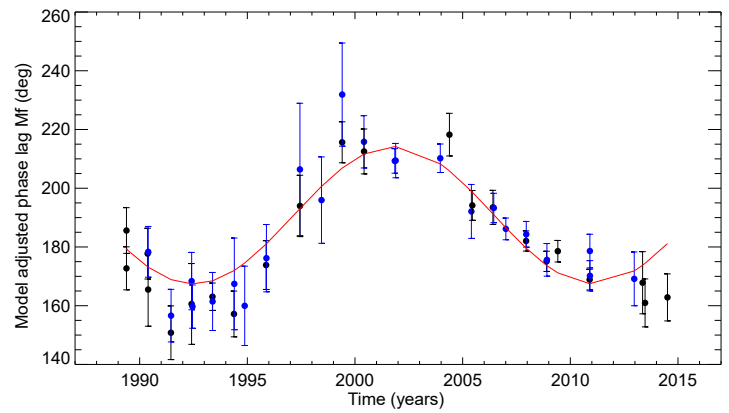

Figure 5. (a) Amplitude (mbar) and (b) phase lag (degrees) of Mf obtained from regression fits to the data from each BPR deployment described in Sect. 2 plotted versus the central date of the record. Error bars show 1 standard error in each parameter. Black and blue points indicate deployments north and south of $58^{\circ} \mathrm{S}$, respectively. Red lines indicate fits with nodal variations as described in the text. Panels (c, $\mathbf{d})$ are the same as (a, b) but with adjustments using the FES2014 model.

values. Once again, the red line shows a cosine fit to the amplitude values. The mean amplitude is $1.34 \pm 0.04$ mbar. However, the amplitude of the cosine is close to zero at $0.00 \pm 0.06$ mbar, or $0.1 \pm 4.2 \%$ of the mean value (with the correct negative sign of Eq. 8). This is much lower than the $13 \%$ expected from the equilibrium tide, so there is approximately a $3 \sigma$ difference between measurements and expectations.

The individual phase lags obtained for Mm (Fig. 6b) are similar on each side of the Drake Passage. However, they have large uncertainties. Weighting each phase lag as for Mf above gives a south-north difference of $2 \pm 3^{\circ}$. They have no evident nodal variation, as suggested by Eq. (8). Therefore, in this case, instead of a nodal fit, the red line in Fig. 6b indicates the median phase lag of $177.3 \pm 4.4^{\circ}$. This value is consistent with equilibrium expectations for a long-period tide at this latitude.

The third long-period tide to be investigated is Mt (period of 9.13 days). This is the next largest long-period tide in the equilibrium tide, with an amplitude about one-third that of $\mathrm{Mm}$ and one-sixth that of $\mathrm{Mf}$, and with a nodal variation in $f$ and $u$ similar to that for Mf in Eq. (4). In this case, the amplitudes are so small that the contribution of Mt to the BP time series is not readily apparent by eye, such as in Fig. 4a and b, although Mt is undoubtedly present as shown in Fig. $3 a$ and b. Therefore, in this case, one has to rely on the formal uncertainties provided by the regression fits.

Figure 7a shows the amplitudes obtained for Mt, which are similar on the north and south sides of the Drake Passage, with a mean value of $0.43 \pm 0.04 \mathrm{mbar}$. The red line indicates a nodal variation with an amplitude of $0.12 \pm 0.06 \mathrm{mbar}$, or $28 \pm 13 \%$ of the mean value, which is consistent with $f$ in Eq. (4) within the uncertainties. Figure 7b shows the estimated phase lags from the analysis of each record. Phase lags have smaller uncertainties after 2001, which follows from the larger amplitudes on average in the second half of the data (Fig. 7a). They have an average value of $197.3 \pm 5.0^{\circ}$. A weighted fit indicates phase lags $22 \pm 9^{\circ}$ larger on the south side. A sinusoidal fit to all of the phase lag values considered together results in an amplitude of $30 \pm 7^{\circ}$, consistent with Eq. (4).

\subsection{Vernadsky data}

Vernadsky Research Base on the west coast of the Antarctic Peninsula (Fig. 2) has the longest tide gauge record in 
(a)

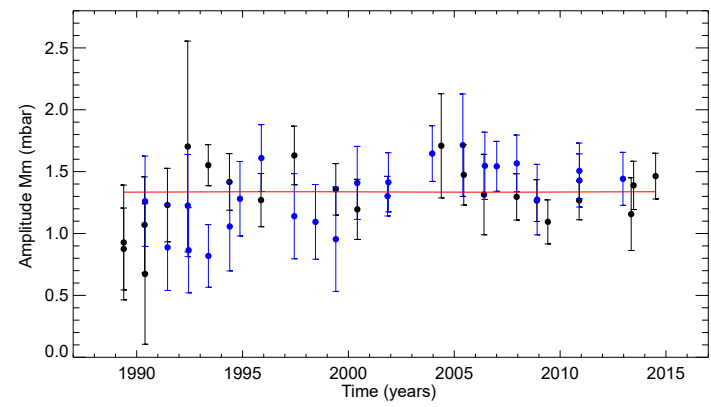

(c)

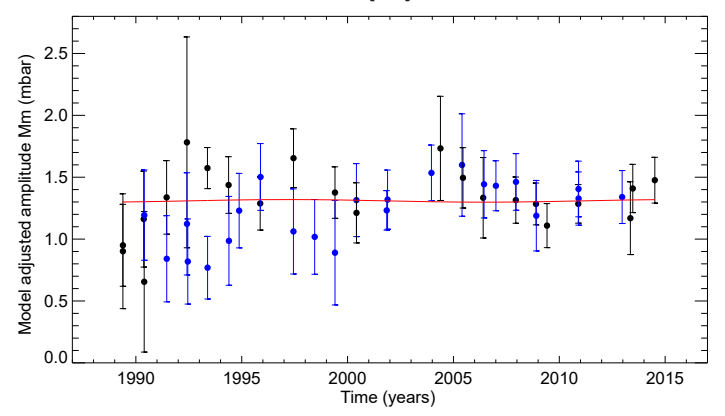

(b)

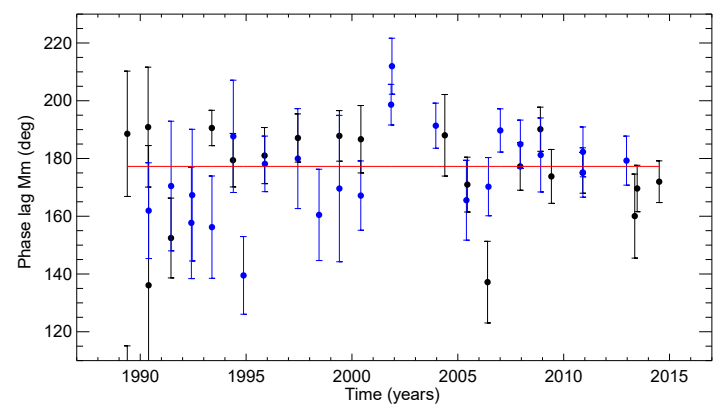

(d)

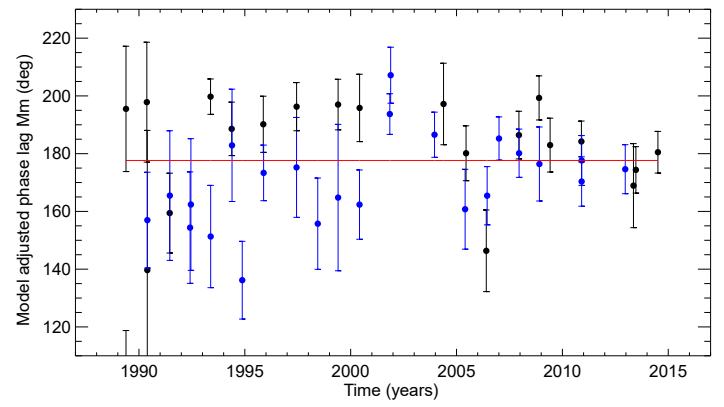

Figure 6. Panels $(\mathbf{a}, \mathbf{b})$ are the same as Fig. 5a, b but for the Mm long-period tide. The red line in panel (b) indicates the median phase lag instead of a nodal fit. Panels $(\mathbf{c}, \mathbf{d})$ are the same as $(\mathbf{a}, \mathbf{b})$ but with adjustments for different deployment locations using the FES2014 model.

Antarctica. The base is now operated by the National Antarctic Scientific Center of Ukraine. A float gauge was installed at the base (then called Faraday) at around the time of the International Geophysical Year (1957-1958). Monthly mean sea levels are available from the PSMSL starting in 1958, while hourly values from March 1984 to December 2014 can be obtained from the Global Extreme Sea Level Analysis (GESLA) data set (http://www.gesla.org, last access: 1 June 2018; Woodworth et al., 2017).

Vernadsky tide gauge data have been used in several studies of ACC variability alongside the information from the Drake Passage BPRs (Hughes et al., 2003; Woodworth et al., 2006). For present purposes, Vernadsky data enable an interesting comparison to be made on how much better Mf can be observed in BP measurements than in coastal tide gauge data. It might be supposed that Vernadsky data would have an advantage in being all from the same location, rather than at different positions for the BPR deployments. On the other hand, a coastal tide gauge record will clearly contain a considerable amount of non-tidal variability due to storm surges, etc.

Figure $3 \mathrm{c}$ shows the spectrum of sea level variability at Vernadsky. Comparison with Fig. 3a demonstrates an order of magnitude larger amount of non-tidal background in Fig. 3c, with only Mf observed clearly, only a hint of Mm, and Mt hidden within the background. Each year of hourly data from Vernadsky was analysed in a similar way as described for the BP measurements, providing daily values of sea level from which estimates of Mf amplitude and phase lag were obtained. (Given the high noise levels at $\mathrm{Mm}$ and Mt frequencies in Fig. 3c, we considered similar analyses for them to be unfeasible.) Figure 8 a shows the amplitude values, which have individual uncertainties approximately 5 times larger than for the BPRs in Fig. 5a. The mean amplitude in the plot is $2.90 \pm 0.25 \mathrm{~cm}$ (and so the Mf harmonic constant would have an amplitude of $2.90 / 1.043=2.78 \mathrm{~cm}$ ). This is larger than for the nearby BPRs. The nodal cycle shown in red has an amplitude of $1.20 \pm 0.36 \mathrm{~cm}$, or $41 \pm 12 \%$ of the mean value, almost exactly the same as for the BPRs and again consistent with expectations from Eq. (4). Phase lag (Fig. 8b) is also consistent with the BP data, having an average value of $184.9 \pm 4.7^{\circ}$. Within the large scatter from year to year, a nodal variation with an amplitude of $22.1 \pm 7.5^{\circ}$ can be just about discerned. (A total of 5 years of data with phase lags outside the plot limits were not used in this nodal fit.)

Therefore, comparisons of Figs. 5 and 8 demonstrate the superiority of BP measurements compared to coastal tide gauge records in long-period tidal studies, unless the nontidal background in the latter can be modelled efficiently. Crawford (1982) provides an earlier example of an attempt at such modelling in Canadian tide gauge data. 
(a)

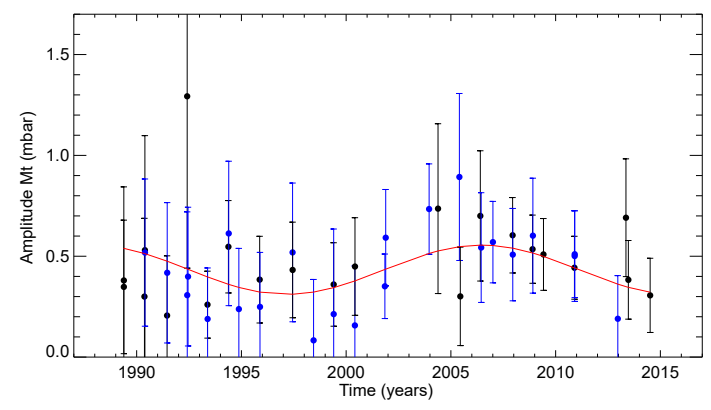

(c)

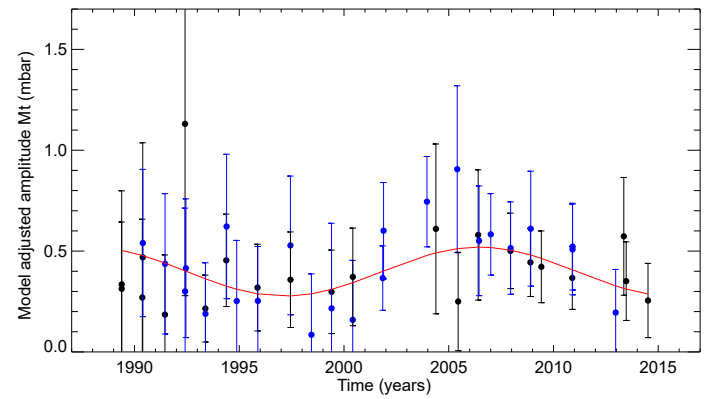

(b)

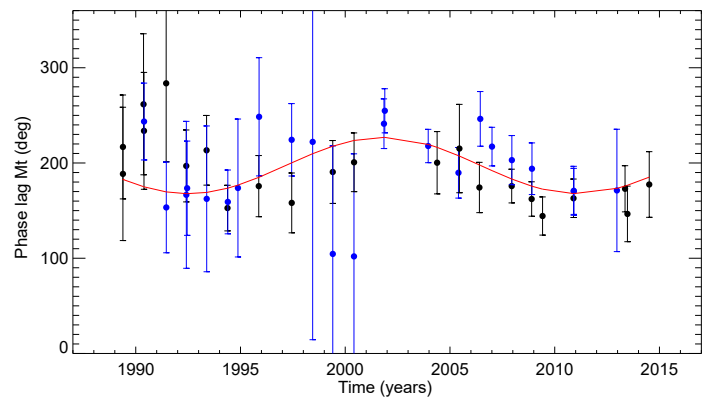

(d)

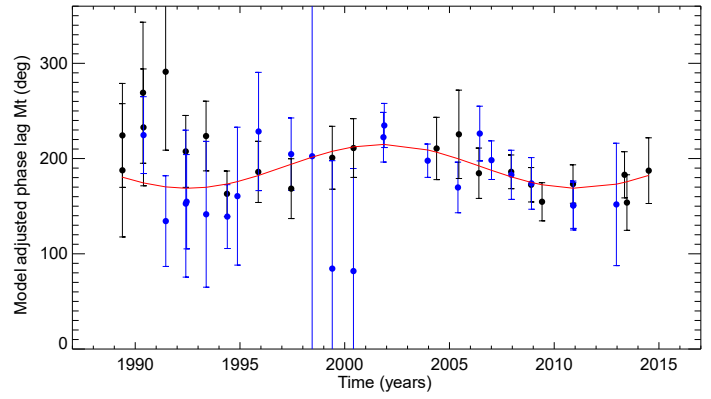

Figure 7. Panels (a, b) are the same as Fig. 5a, b but for the Mt long-period tide. Panels (c, d) are the same as (a, b) but with adjustments using the FES2014 model.

Fortunately, dynamic atmospheric correction (DAC) data sets are now available which provide estimates of the sea level response to air pressures and winds every $6 \mathrm{~h}$ on a $0.25^{\circ}$ global grid. Estimates are based on the use of a highresolution barotropic model for high-frequency variability (timescales less than 20 days) and the assumption of the inverse barometer response for longer timescales. Details are available from the Archivage, Validation et Interprétation des données des Satellites Océanographiques (AVISO) website (https://www.aviso.altimetry.fr, last access: 1 June 2018). Carrère and Lyard (2003) demonstrated how effective such modelling could be in estimating non-tidal variability in tide gauge records.

Figure $3 \mathrm{~d}$ shows the spectrum of sea level variability at Vernadsky once the DAC correction has been applied. Complete years of DAC corrections are available for 1993 onwards. Therefore, they have been employed for the 22-year period of 1993-2014 only. Comparison to Fig. 3c shows that most of the background has been modelled effectively, down to a level a little greater than that for the BPRs in Fig. 3a, and that Mf, Mm and Mt can now all be clearly identified above the background. Figure 8c-h contain a set of analyses of nodal variations for Mf amplitude and phase lag (Fig. 8c and d), Mm (Fig. 8e and f) and Mt (Fig. 8g and h), all based on the DAC-corrected data for 1993-2014. In the case of Mf (Fig. $8 \mathrm{c}$ and d), the mean amplitude is $2.59 \pm 0.13 \mathrm{~cm}$ (and so the Mf harmonic amplitude is $2.59 / 1.043=2.49 \mathrm{~cm}$ ). The nodal cycle in red has an amplitude of $1.05 \pm 0.19 \mathrm{~cm}$, or $41 \pm$ $7 \%$, about the same as for the uncorrected data in Fig. 8a. Average phase lag (Fig. 8d) has a value of $207.7 \pm 2.9^{\circ}$ (approximately $23^{\circ}$ larger than for the uncorrected data), and now a clear nodal cycle can be seen with an amplitude of $23.4 \pm 4.0^{\circ}$ (without the need to reject any values for being outside plot limits).

In the case of Mm (Fig. 8e), the average amplitude is $1.47 \pm 0.13 \mathrm{~cm}$, while the nodal fit has an amplitude of $10 \pm$ $13 \%$ of the average but with the opposite sign expected from Eq. (8). This finding is similar to the difficulty of explaining Mm amplitude from the BPR data in Fig. 6a reported above, and discussed further in the following section. Phase lag for Mm (Fig. 8f) has an average value of $174.0 \pm 6.8^{\circ}$, with no evident nodal variation as expected from Eq. (8). The average amplitude of Mt (Fig. 8g) is $0.57 \pm 0.13 \mathrm{~cm}$ with a nodal variation of $13 \pm 34 \%$ of the mean, while Fig. 8h shows an average phase lag of $232.6 \pm 12.4^{\circ}$ and a nodal amplitude of $47.3 \pm 19.2^{\circ}$.

Overall, one can see the benefit of using the DAC corrections. The non-tidal variability in the sea level spectrum is much reduced, and nodal variations in all three long-period tides can now be investigated more reliably. Mf and Mt amplitudes and phase lags, and $\mathrm{Mm}$ phase lag, are generally consistent with equilibrium expectations, $\mathrm{Mm}$ amplitude be- 
(a)

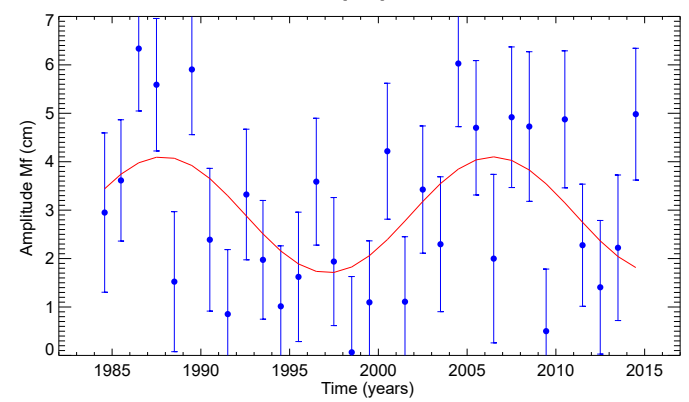

(c)

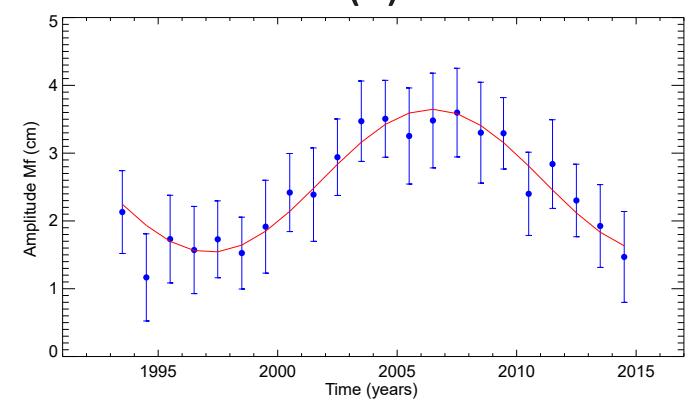

(e)

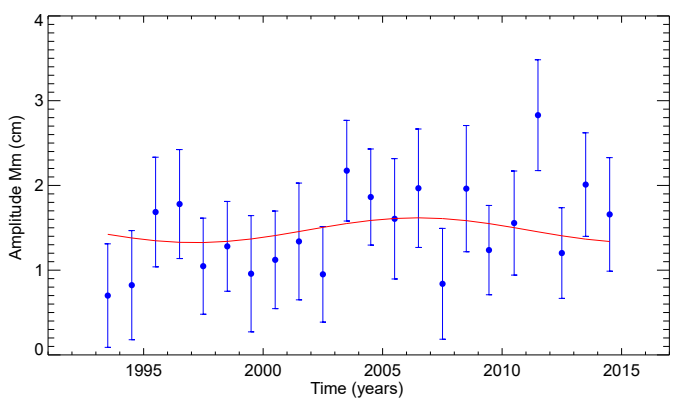

(g)

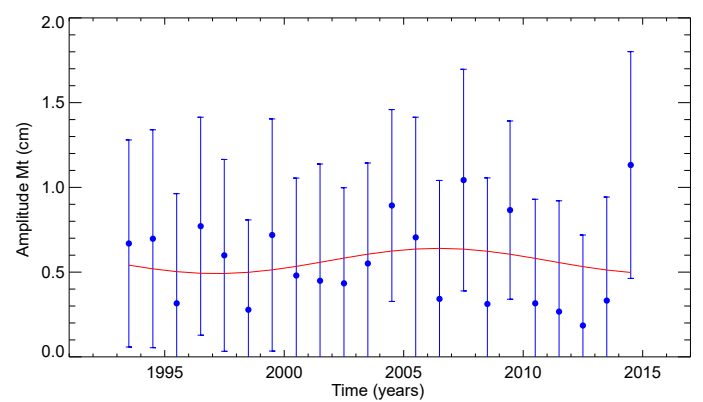

(b)

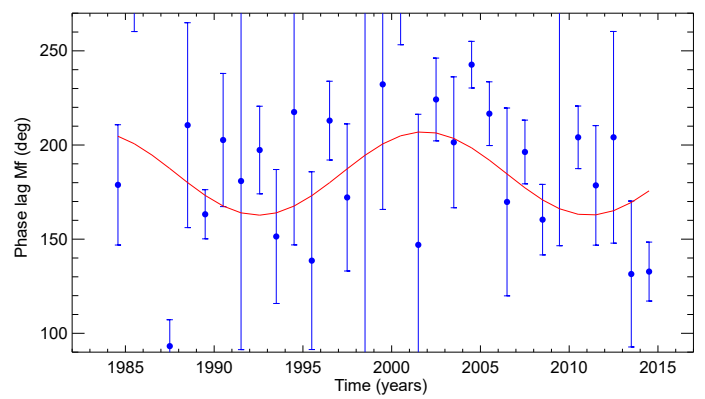

(d)

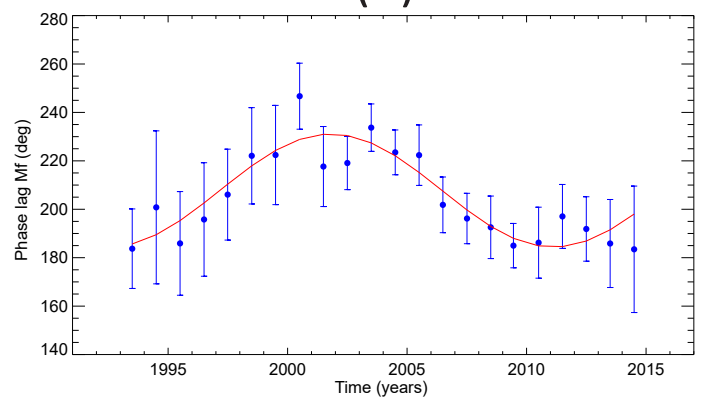

(f)

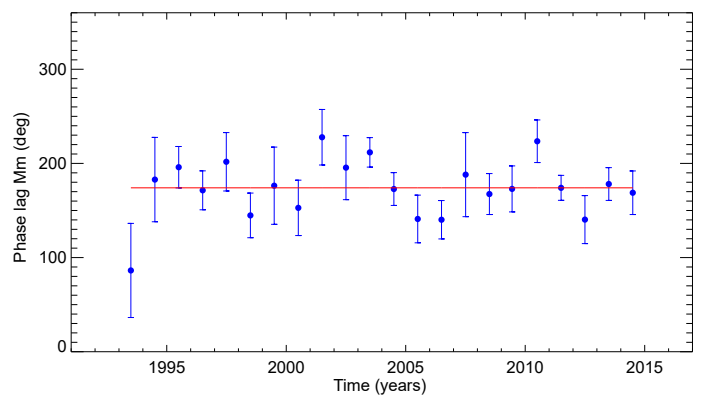

(h)

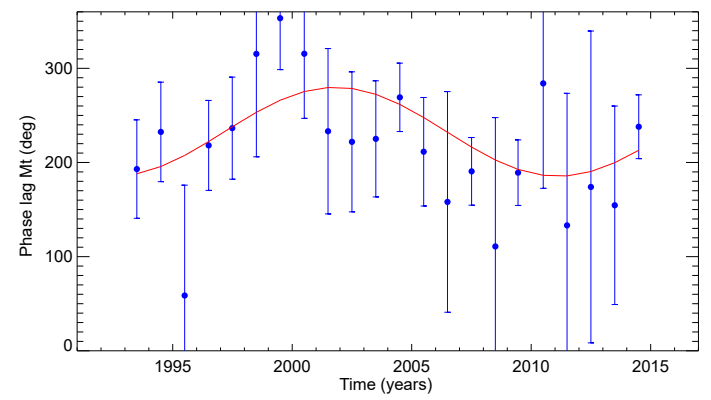

Figure 8. (a) Amplitude (cm) and (b) phase lag (degrees) of Mf obtained from Vernadsky tide gauge data. Panels (c, d) are the same as (a, b) for Mf but using DAC-corrected tide gauge data. Panels (e, f) are the same as (a, b) but for the Mm long-period tide and using DACcorrected data. The red line in panel (f) indicates the median phase lag instead of a nodal fit. Panels (g, h) are the same as (a, b) but for Mt and using DAC-corrected data. 
Table 1. A summary of estimates of nodal variation parameters for each long-period tide from Drake Passage BPR and Vernadsky tide gauge data. The last column shows the corresponding value in the equilibrium tide and appropriate equation number in the text.

\begin{tabular}{|c|c|c|c|}
\hline $\begin{array}{l}\text { Long-period tide } \\
\text { and nodal } \\
\text { parameter }\end{array}$ & $\begin{array}{l}\text { Amplitude of } \\
\text { variation }\end{array}$ & $\begin{array}{l}\text { Section in the paper } \\
\text { where discussed }\end{array}$ & $\begin{array}{l}\text { Corresponding amplitude } \\
\text { in equilibrium tide } \\
\text { [equation number in text] } \\
\text { (and see references given in } \\
\text { the text) }\end{array}$ \\
\hline Mf " $f$ " & $43 \pm 3 \%$ & $\begin{array}{l}\text { BPR data discussed in } \\
\text { Sect. } 3.1\end{array}$ & $40 \%[4]$ \\
\hline Mf “ $u ”$ & $28.4 \pm 1.4^{\circ}$ & & $23.7^{\circ}[4]$ \\
\hline $\mathrm{Mm}$ " $f$ " & $0.1 \pm 4.2 \%$ & & $13 \%[8]$ \\
\hline Mm " $u "$ & $\begin{array}{l}\text { No evident } \\
\text { variation; see text }\end{array}$ & & Zero [8] \\
\hline Mt " $f$ " & $28 \pm 13 \%$ & & $40 \%[4]$ \\
\hline Mt " $u "$ & $30 \pm 7^{\circ}$ & & $23.7^{\circ}[4]$ \\
\hline Mf " $f$ " & $43 \pm 3 \%$ & $\begin{array}{l}\text { BPR data, adjusted for } \\
\text { deployments being at } \\
\text { different locations } \\
\text { using the FES2014 } \\
\text { model, discussed in } \\
\text { Sect. } 4\end{array}$ & $\begin{array}{l}\text { As above for each } \\
\text { long-period tide }\end{array}$ \\
\hline Mf “ $u ”$ & $23.4 \pm 1.4^{\circ}$ & & \\
\hline Mm “ $f$ " & $0.8 \pm 4.3 \%$ & & \\
\hline Mm “ $u$ ” & $\begin{array}{l}\text { No evident } \\
\text { variation; see text }\end{array}$ & & \\
\hline Mt " $f$ " & $31 \pm 14 \%$ & & \\
\hline $\mathrm{Mt} " u$ " & $23.0 \pm 6.9^{\circ}$ & & \\
\hline Mf " $f$ " & $41 \pm 12 \%$ & $\begin{array}{l}\text { Vernadsky tide gauge } \\
\text { data spanning } 1984-2014 \text {, } \\
\text { discussed in Sect. } 3.2\end{array}$ & $\begin{array}{l}\text { As above for each } \\
\text { long-period tide }\end{array}$ \\
\hline Mf “ $u$ ” & $22.1 \pm 7.5^{\circ}$ & & \\
\hline Mf " $f$ " & $41 \pm 7 \%$ & $\begin{array}{l}\text { Vernadsky tide gauge } \\
\text { data spanning 1993-2014 } \\
\text { with non-tidal } \\
\text { variability removed } \\
\text { using the DAC model }\end{array}$ & $\begin{array}{l}\text { As above for each } \\
\text { long-period tide }\end{array}$ \\
\hline Mf “ $u ”$ & $23.4 \pm 4.0^{\circ}$ & & \\
\hline Mm " $f$ " & $\begin{array}{l}10 \pm 13 \% \text {; note } \\
\text { opposite sign to } \\
\text { that predicted by } \\
\text { the equilibrium } \\
\text { tide; see text }\end{array}$ & & \\
\hline Mm " $u$ " & $\begin{array}{l}\text { No evident } \\
\text { variation; see text }\end{array}$ & & \\
\hline Mt " $f$ " & $13 \pm 34 \%$ & & \\
\hline Mt " $u$ " & $47.3 \pm 19.2^{\circ}$ & & \\
\hline
\end{tabular}

ing an exception to be discussed further below. All the above Vernadsky findings are summarised in Table 1.

\section{Discussion}

Some of the findings of the previous section are consistent with expectations from the equilibrium tide, while those that are not require explanation.
As mentioned above, the long-period tides in the equilibrium tide have simple spatial distributions in amplitude and phase, with north-south variations only. However, their spatial distributions in the real ocean are now known to depart considerably from equilibrium expectations, with larger departures at shorter periods (e.g. see Fig. 2 of Ray and Erofeeva, 2014). These differences are most evident when con- 
(a) f from Eq. A2 (red) and Doodson (blue)

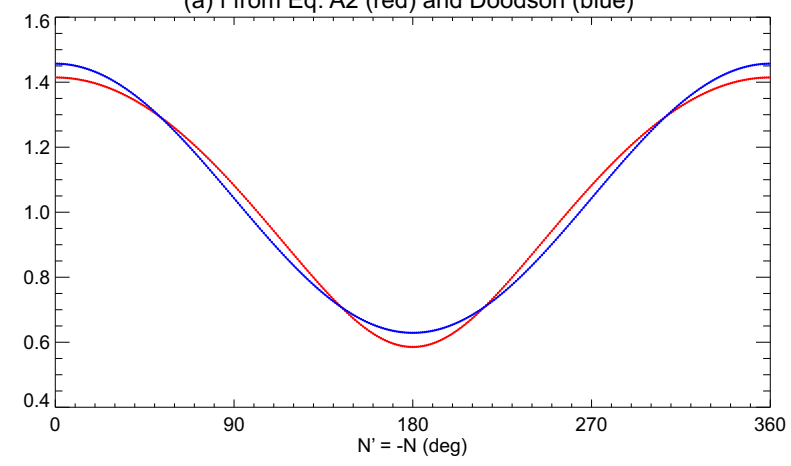

(b) u from Eq. A6. (red) and Doodson (blue)

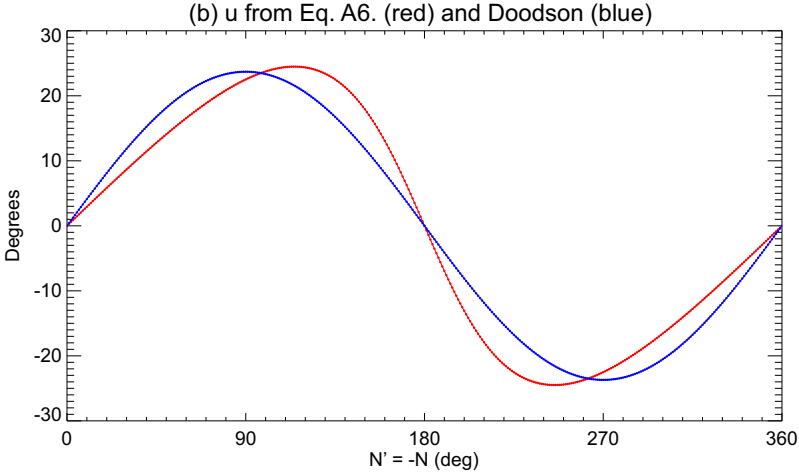

Figure 9. Values of (a) $f$ and (b) $u$ for Mf computed by Eqs. (A2) and (A6) (red) or using the Doodson parameterisations (blue) as a function of $N^{\prime}=-N, N$ being the longitude of the lunar ascending node.

trasting the Pacific, Atlantic and Indian Ocean low-latitude and midlatitude basins.

If one considers Mf in particular, atlases of this constituent have been available for many years, notably since the data assimilation numerical modelling of Schwiderski (1982). More recent co-tidal distributions for Mf have been obtained from altimeter measurements and models by Kantha et al. (1998, Fig. 7), Mathers and Woodworth (2001, Plate 4) and Egbert and Ray (2003, Fig. 1). These are consistent with Mf phase lag increasing when travelling south down the Pacific coast of South America, with the $180^{\circ}$ contour around the Drake Passage, and with a complicated amphidromic pattern in the South Atlantic to the NE of the Falklands. More recent studies have included the development of the FES2004 ocean tide model, which also showed these features (Lyard et al., 2006, Fig. 2), with roughly the same Mf amplitude on both sides of the Drake Passage and larger phase lag on the south side than on the north side.

FES2014 (Finite Element Solution 2014) is the latest in the series of state-of-the-art global ocean tide models provided by French groups. It provides elevations and currents (amplitude and phase) and tidal loading information for 34 tidal constituents on a global $1 / 16^{\circ} \times 1 / 16^{\circ}$ grid. FES2014 (2018) provides more detailed information.

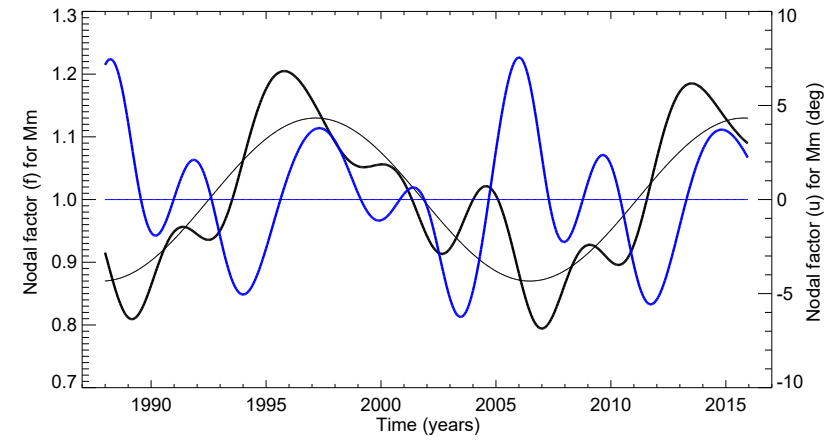

Figure 10. The nodal factors $f$ and $u$ for $\mathrm{Mm}$ at $58^{\circ} \mathrm{S}$. The two approximately equal nodal sidebands result in the $f$ and $u$ in Eq. (8) (or Eq. A8), as indicated by the thin black and blue lines, respectively, with values shown on the left and right axes, respectively. The overall values of $f$ and $u$ for Mm, after taking into account the sidebands included in Eq. (A9), are shown by the thick black and blue lines, respectively.

Figure S2a and b show the Mf amplitude and phase lag for Mf at the Drake Passage from the FES2014 model. Some points of consistency with our findings are as follows. First, the model has much the same amplitude over the whole area $(\sim 2 \mathrm{~cm})$, and phase lags are essentially zonal, largely justifying our decision to combine amplitudes and phase lags from all deployments in Fig. 5, and the subsequent discussion in terms of north- and south-side values.

Second, we found the amplitudes for Mf to be similar on the north and south sides of the Drake Passage (Fig. 5a), but phase lags were shown to be $22 \pm 2^{\circ}$ larger for the southern deployments (Fig. 5b). The latter is qualitatively consistent with Fig. S2b. Third, the $192^{\circ}$ average phase lag for Mf from all the BPRs taken together (Sect. 3.1, Fig. 5b) is consistent with the $\sim 190^{\circ}$ contour in mid-passage in Fig. S2b. In addition, the Mf harmonic constants estimated above for Vernadsky using DAC-corrected data $(2.49 \mathrm{~cm}$ amplitude and $208^{\circ}$ phase lag) are similar to those in FES2014 $(2.41 \mathrm{~cm}$ and $202^{\circ}$, respectively). FES2014 amplitudes and phase lags for $\mathrm{Mm}$ and $\mathrm{Mt}\left(1.31 \mathrm{~cm}\right.$ and $190^{\circ}$ and $0.42 \mathrm{~cm}$ and $211^{\circ}$, respectively) are all consistent with DAC-corrected Vernadsky findings to within $\sim 1$ or $\sim 2 \mathrm{SD}$ (standard deviations) for amplitudes and phase lags, respectively.

If a tide model such as FES2014 was perfect, then any differences in observed amplitudes and phase lags due to the different deployment locations could be removed by relating each set of findings to those which would have been obtained at a reference location, using an admittance relationship:

$H_{i}^{\mathrm{ref}}=H_{i} \frac{H M^{\mathrm{ref}}}{H M_{i}}$,

where $H_{i}$ is the measured amplitude for deployment $i$, $H M_{i}$ and $H M^{\text {ref }}$ are the model amplitudes at the deployment and reference point locations, respectively, and $H_{i}^{\text {ref }}$ is the inferred amplitude at the reference point. Similarly, 
$\varphi_{i}^{\mathrm{ref}}=\varphi_{i}+\varphi M^{\mathrm{ref}}-\varphi M_{i}$,

where $\varphi_{i}$ is the measured phase lag for deployment $i$, $\varphi M_{i}$ and $\varphi M^{\text {ref }}$ are the model phase lags at the deployment and reference point locations, respectively, and $\varphi_{i}^{\text {ref }}$ is the inferred phase lag at the reference point. If the model represented the spatial dependence of the tide correctly, then $H_{i}^{\text {ref }}$ and $\varphi_{i}^{\text {ref }}$ should have only a temporal dependence.

Figure $5 \mathrm{c}$ shows the resulting model-adjusted values of $\mathrm{Mf}$ amplitude, using a reference point location of $57^{\circ} \mathrm{W}, 58^{\circ} \mathrm{S}$, demonstrating satisfactory consistency between values north and south. That was already the case in Fig. 5a, and the similarity of Fig. 5a and c reflects the uniformity of amplitude in the model in this area. The nodal fit in red shows a cosine with an amplitude of $43 \pm 3 \%$ of the mean, which is identical to that in Fig. 5a. For phase lag, Fig. 5d demonstrates a considerable improvement compared to Fig. 5b, with values north and south in agreement (weighted south-north difference of $0 \pm 2^{\circ}$ ). In addition, the nodal fit in red has an amplitude of $23.4 \pm 1.4^{\circ}$, which is closer to Eq. (4) than that for Fig. $5 b$.

Consequently, the temporal variation of Mf can be seen from Fig. 5 to conform closely to expectations from its equilibrium form shown by Eq. (4). Mf has the largest amplitude of the long-period tides we have investigated, which together with its relatively short period compared to the typically 1year long records, means that it is the best resolved. Our finding of consistency with equilibrium expectations parallels an observation regarding fortnightly variations in the solid Earth in a study of polar motion data by Ray and Egbert (2012), who concluded that a similar admittance applied to Mf and its nodal sideband (see also earlier work by Gross, 2009). As explained above, the same admittance for a central frequency and its sidebands indicates that the nodal factors of the equilibrium tide apply equally as well to the tide in the real ocean (or solid Earth).

Turning to Mm, its spatial variation in FES2014 is shown in Fig. S2c and d. Once again, amplitudes are much the same over the whole area, and phase lag contours are roughly zonal. However, in this case, Fig. S2d indicates a north-south gradient of phase lag about half that for Mf in Fig. S2b. Our observation of a small south-north difference of $2 \pm 3^{\circ}$ is qualitatively consistent with the smaller gradient in the model (a south-north difference of $\sim 10^{\circ}$ ). The observed average phase lag of $177^{\circ}$ for $\mathrm{Mm}$ from all deployments combined (Sect. 3.1) is a little lower than the $\sim 185^{\circ}$ contour in mid-passage in Fig. S2d.

Figure 6a shows that Mm amplitudes for the first decade are lower in the south, but they become more equal to the northern ones thereafter. One may note that five of the six deployments with particularly low amplitudes before 1994 are from the F-S line. However, some kind of general amplitude bias in these early deployments is unlikely, given that their corresponding amplitudes for Mf are consistent with later ones (Fig. 5a). Overall, Fig. 6a does not provide evidence for a temporal dependence of $\mathrm{Mm}$ amplitude similar to that of Eq. (8). However, identifying a nodal signal of only $\sim 0.15$ mbar is clearly a challenge given the uncertainties. At least, the absence of any evidence for nodal variation in $\mathrm{Mm}$ phase lag (Fig. 6b) is consistent with Eq. (8).

A nodal variation in amplitude of $\sim 0.15$ mbar might be technically within the resolution of the BPR measurements if $\mathrm{Mm}$ was accompanied by only a limited amount of nontidal variability on similar (monthly) timescales. Monthly timescales are more comparable to processes associated with ACC variability. Sheen et al. (2014) showed that eddy kinetic energy is more intense in the north of the Drake Passage, where the main fronts and their meanders occur. However, eddy activity also occurs in the south. In addition, variability in BP in this region has a contribution on 30- to 70-day timescales from the Madden-Julian Oscillation (Matthews and Meredith, 2004), which could potentially impact our determination of $\mathrm{Mm}$.

An attempt was made to reduce the amount of nontidal variability in the records with the use of 5-day values of BP from the Nucleus for European Modelling of the Ocean (NEMO) $1 / 12^{\circ}$ ocean circulation model for 1988 2012 (Hughes et al., 2018), with the aim of better resolving any nodal tidal signals, particularly that for $\mathrm{Mm}$. The model $\mathrm{BP}$ was found to have a high correlation with measured nontidal BP for most of the southern deployments, while correlations were weaker in the north, as Sheen et al. (2014) would suggest. However, subtraction of the model values from the measurements resulted in little change in the determined $\mathrm{Mm}$ amplitudes and phase lags.

FES2014 model adjustments for Mm from Eqs. (9) and (10) result in Fig. 6c and d. Figure 6c confirms similar amplitudes north and south, and the nodal fit gives an amplitude of $0.8 \pm 4.3 \%$ of the mean value, a little larger than that from Fig. 6a, but still $3 \sigma$ away from that expected in Eq. (8). As for phase lag (Fig. 6d), the weighted south-north difference is now $-11 \pm 3^{\circ}$, as can be readily observed by eye. This indicates that the model overcorrects for spatial variation in phase lag. This suggests that the difference in $\mathrm{Mm}$ phase lag across the real Drake Passage is less than in the model.

One might have expected the detection of Mt to be easier than that of Mm, thanks to its shorter period, even though it has a much smaller amplitude. Figure 7 a shows an average amplitude of 0.43 mbar, with little evidence for differences between values north and south, while Fig. $7 \mathrm{~b}$ indicates an average phase lag of $\sim 197^{\circ}$, and some evidence for phase lags about $22^{\circ}$ larger in the south than in the north. The temporal variations in Mt amplitude and phase lag in Fig. 7a and $b$ are consistent with equilibrium expectations within the large uncertainties for this small constituent.

Figure $\mathrm{S} 2 \mathrm{e}$ and $\mathrm{f}$ give the corresponding information for Mt from the FES2014 model. (This constituent is called Mtm in the model.) Figure S2e shows an amplitude of $\sim 0.4 \mathrm{~cm}$ over most of the area, while Fig. S2f shows a meridional gra- 
dient for phase lag similar to that obtained from the BPRs. The observed mean phase lag of $197^{\circ}$ (Sect. 3.1) is consistent with the mid-passage contour in Fig. S2f.

If one applies the FES2014 model adjustments from Eqs. (9) and (10) to the observed amplitudes and phase lags for Mt, then one obtains Fig. 7c and d. This procedure results in apparent improvements as for Mf. Figure $7 \mathrm{c}$ is much the same as Fig. 7a, with similar amplitudes north and south. The nodal fit in Fig. 7c has an amplitude of $31 \pm 14 \%$ which is similar to that obtained in Sect. 3.1 for Fig. 7a. For phase lag, Fig. $7 \mathrm{~d}$ demonstrates an improvement compared to Fig. $7 \mathrm{~b}$ with a weighted south-north difference of $-5 \pm 9^{\circ}$, consistent with zero difference. The nodal fit shows an amplitude of $23.0 \pm 6.9^{\circ}$, closer to Eq. (4) than the value for Fig. $7 \mathrm{~b}$ obtained in Sect. 3.1.

As an aside, one can mention that Mt is to some extent a "forgotten constituent". It is represented in harmonic expansions of the tidal potential (Doodson, 1921; Cartwright and Tayler, 1971) as a line with Doodson number $0,3,0,-1,0,0$ (or 085.455 in Doodson's notation) with one major nodal sideband $(0,3,0,-1,1,0)$. However, Doodson did not usually refer to it explicitly in his own papers (e.g. Doodson, 1928), and it is not included in the standard sets of harmonic constituents used in tidal analysis packages (e.g. Bell et al., 1996), even though Fig. 3 shows that it is resolvable at higher latitudes, at least in BPR data. One supposes that the reason for lack of interest in this constituent by previous tidal analysts has been due to its smaller amplitude at low latitudes and midlatitudes and to the generally higher level of noise in tide gauge records.

There are several complications we are aware of in the above analyses. One is that when measurements are combined from different locations, the observed tidal amplitudes should be adjusted for spatial variations in water density, latitude-dependent variations in acceleration due to gravity and depth-dependent compressibility of seawater. However, these will be at the $\sim 1 \%$ level (Ray, 2013) and so are much less than other uncertainties.

A second complication concerns whether imperfections in our tidal analyses and subsequent averaging of the BP residuals into daily means of BP could have aliased residual components of the main diurnal and semi-diurnal tides into frequencies similar to those of the three long-period tides. We do not believe this is an important issue. All of the tidal analyses were subjected to quality control to check that tidal and non-tidal components of the records were separated efficiently. However, any residual tidal signals would then have been considerably reduced by the daily averaging. For example, the amplitude of any residual M2 would have been reduced to approximately $3.5 \%$ of its original value and aliased into the period of MSf (14.77 days). Consequently, while it is possible that aliasing could have contributed to some of the MSf in Fig. 3a, we believe most of that to be real. Furthermore, it is hard to see how the observed Mf, Mm and Mt could have been affected to any significant extent by aliasing.
In principle, residuals of the tiny constituents OP2, Lambda2 and SNK2 could be aliased into Mf, Mm and Mt, respectively, although reduced to negligibility by the daily averaging. Lambda 2 is included explicitly in the tidal analysis. The other two are interaction constituents (see below) and do not appear as significant lines in the tidal potential (Cartwright and Tayler, 1971).

A further complication is that there will be other constituents present in the data (i.e. genuine and not-aliased ones) with a similar period to Mf, Mm or Mt. We have ignored this complication for present purposes as the other constituents are likely to be small. In the case of Mf, the other main constituent will be MSf. MSf has an amplitude $9 \%$ of that of $\mathrm{Mf}$ in the equilibrium tide, which is similar to that found in the composite BPR record (Fig. 3a). Similarly, MSm (period of 31.81 days) has an amplitude of $19 \%$ of $\mathrm{Mm}$ in the equilibrium tide, and MSt (period of 9.56 days) is $19 \%$ of Mt. However, there is little evidence for significant amounts of either in Fig. 3a. In principle, these other constituents should be separable from Mf, Mm and Mt given a year of data. One might imagine a more sophisticated harmonic expansion in future work in which information on these and other constituents is inferred from ocean tide models.

Another complication is that observations of the three long-period tides considered here can contain contributions from non-linear interactions between shorter-period tides. For example, the difference between $\mathrm{K} 1$ and $\mathrm{O} 1$ frequencies is identical to that of Mf, and so their interaction can contribute to the observed Mf. K2 and M2 interactions can also contribute. Similarly, M2 and S2 can provide an interaction with the same frequency as MSf, which is similar to that of Mf. N2 and M2 interaction can contribute to Mm. An interaction will have an $f$ and $u$ determined by the product of the individual $f$ and $u$ values of the two short-period tides involved (see Table 4.4 of Pugh and Woodworth, 2014). Therefore, interaction nodal factors will be different from those of the long-period tide. This complication is primarily an issue for shallow waters, rather than the deeper ocean areas of the Drake Passage where our BPR measurements are located. Nevertheless, it should be possible to estimate the contributions from such interactions using tide modelling.

A final complication relates to all BP spectra having a continuous non-tidal background in addition to a tidal line spectrum (e.g. Fig. 3). The background will tend to increase the amplitudes calculated for each tidal constituent (see Appendix B of Munk and Cartwright, 1966 and discussion in Wunsch, 1967). We simply note that this aspect would impact primarily our determination of $\mathrm{Mm}$. Another issue to do with the background is that it is not white noise. As mentioned above, this could lead to the errors in the harmonic analysis regressions being underestimated (e.g. Williams, 2003). In fact, the background spectra for all of the 45 BPR deployments are similar and can be parameterised reasonably well by a (frequency ${ }^{k}$ ) dependence where $k \sim-1.5$ (Fig. S3). 
This suggests similar biases in estimated errors for each constituent for each deployment. Such biases, as long as they are similar in each case, should not significantly affect the fits to determined parameters from all deployments in Figs. 5-7.

\section{Conclusions}

If one has several decades (or at least 19 years) of good tide gauge (or, in theory, BPR) data available for a tidal analysis then, if background noise levels allow, it should be possible to avoid having to consider the nodal sidebands as perturbations of the main harmonic via the use of "nodal factors" $f$ and $u$. Instead, one can treat them as independent constituents and make an explicit determination of their amplitudes and phase lags. Examples of such analyses of long records include those of Amin (1983) and Foreman and Neufeld (1991).

However, in practice, most tidal analyses are made using one or several years of data, for which assumptions are required for $f$ and $u$. The drawbacks of this approach have been recognised for many years but primarily for the semidiurnal and diurnal constituents. As far as we know, the question of whether the variation of the long-period tides through the nodal cycle differs from equilibrium expectations has never been investigated properly.

In this paper, we have used data from 45 separate BPR deployments in the Drake Passage, and 31 years of hourly tide gauge data from the Vernadsky Research Base in Antarctica, to estimate how well the nodal variation of the amplitudes and phase lags of Mf, Mm and Mt compares to expectations from the equilibrium tide. Our analysis uses simple harmonic expansions of daily values of $\mathrm{BP}$ or sea level at each location.

The combined data set provides information on how the amplitudes and phase lags of each constituent vary between the north and south sides of the Drake Passage. The measurements indicate that amplitudes are similar throughout the region, which is consistent with a state-of-the-art ocean tide model (FES2014, 2018). Phase lags for Mf and Mt are $\sim 20^{\circ}$ larger in the south than in the north, which is also consistent with the model. However, the observed south-north difference in $\mathrm{Mm}$ phase lag is consistent with zero, compared to $\sim 10^{\circ}$ in the model. In fact, the Mm difference is probably consistent with the model given the uncertainties, and at least the BPR data and FES2014 are in agreement on indicating a smaller meridional gradient for $\mathrm{Mm}$ phase lag than for the other two constituents. Any detailed differences for all the long-period tides may be understood better by future modelling.

However, our main interest is in the temporal variability of the long-period tides. The variation of the amplitudes and phase lags of Mf and Mt in the BPR data has been found to be consistent with that suggested by the equilibrium tide within their uncertainties. To a great extent this is an expected finding given that, as explained in the introduction, the long-period tides are closer to equilibrium than the diurnal and semi-diurnal tides, and the frequencies of the nodal sidebands are close to that of the central line. Nevertheless, this is a reassuring finding for tidal analysts who might now (in this region at least) be able to employ $f$ and $u$ for the long-period tides as anticipated. The variation in phase lag of $\mathrm{Mm}$ (or rather its non-variation) is also consistent with equilibrium expectations. The absence of an expected $13 \%$ variation in the amplitude of Mm (Eq. 8) at $3 \sigma$ level (or possibly less if, as explained above, our uncertainties were slightly underestimated) is probably due to the background of nontidal variability in the ocean circulation in this energetic area and/or in our inability to account adequately for spatial variations in Mm amplitude with the use of FES2014.

Our study has shown clearly that BPR data have advantages over conventional tide gauge measurements in longperiod tidal studies such as this. Section 3.2 showed that, when Vernadsky coastal tide gauge data were corrected for non-tidal variability, a major improvement in identification of the long-period tides results (e.g. reduction in the uncertainties for Mf in Table 1 by a factor of 2). However, the Drake Passage BPRs, which were located in deeper water where the inverse barometer-related sea level variations are compensated automatically by BP itself, have still provided more accurate estimates of nodal variation, in spite of different locations for deployments. Table 1 demonstrates that the uncertainties for Vernadsky Mf, even when DAC-corrected, are still double those of the FES2014-corrected BPRs. (A similar conclusion can be obtained from inspection of the uncertainties displayed in Figs. 5c, d and 8c, d.) Nevertheless, it is the case that there is a lot more tide gauge data available for study worldwide than BPR data (Woodworth et al., 2017). Therefore, an obvious recommendation following from the present work is that tide gauge data be investigated more completely in order to investigate whether the temporal variation of long-period tides conforms to equilibrium expectations, perhaps by employing "stacks" of records, as has been used previously to investigate other long-period components of tide gauge records (e.g. Trupin and Wahr, 1990), with DAC-type corrections applied to each record.

Data availability. All data used in this paper may be obtained from the websites mentioned in the text. 


\section{Appendix A: The accuracy of Doodson's nodal factors}

The formulae for $f$ and $u$ presented in Doodson (1928) and Doodson and Warburg (1941) are more complicated than those in Eqs. (3), (4) or (8), in that they include additional terms depending on the cosines and sines of $2 N$ and $3 N$. However, the ones we have used are adequate for the present paper. It is useful to explain where they come from.

Imagine a constituent of unit amplitude described schematically by $\cos (\omega t)$, where for simplicity we have ignored the $A$ and $G$ in Eq. (2). Consider the constituent as having a single important nodal sideband with an amplitude $R$ which is less than 1 , and an angular frequency $\omega+n$, where $n=\left(\frac{2 \pi}{18.61 \text { years }}\right)$ is the angular frequency of the nodal angle $N^{\prime}=-N$ (Doodson, 1921). This $\omega+n$ situation represents Mf and its sidebands. Mt and K2 can be represented similarly. M2 has its single important sideband at $\omega-n$. Although most lunar constituents have one sideband that is much larger than the other, there are some constituents for which the amplitudes of the sidebands are approximately the same, such as $\mathrm{Mm}$; see below.

Therefore, in the example of Mf, we can express the total tide as

$$
\begin{aligned}
\cos (w t)+R \cos ((w+n) t) & =[1+R \cos (n t)] \cos (w t) \\
& -[R \sin (n t)] \sin (w t) .
\end{aligned}
$$

The nodal factor for amplitude $(f)$ can then be expressed by

$$
\begin{aligned}
f^{2} & =1+R^{2} \cos (n t)^{2}+2 R \cos (n t)+R^{2} \sin (n t)^{2} \\
& =1+R^{2}+2 R \cos (n t) \\
f & =\sqrt{1+R^{2}} \sqrt{1+\frac{2 R \cos (n t)}{1+R^{2}}} .
\end{aligned}
$$

We can expand the second square root by a Maclaurin series:

$$
f=\sqrt{1+R^{2}}\left[1+\left(\frac{2 R}{1+R^{2}}\right) \frac{\cos (n t)}{2}-\left(\frac{2 R}{1+R^{2}}\right)^{2} \frac{\cos (n t)^{2}}{8} \text { etc. }\right],
$$

from which the second term provides the nodal time dependence of $f$, i.e. $\frac{R \cos (n t)}{\sqrt{1+R^{2}}}$. When $R$ is very small, this is simply $R \cos (n t)$. (In the case of $\mathrm{M} 2$, for which the sideband is at $\omega-n$, it becomes $-R \cos (n t)=-0.037 \cos (n t)$, as in Eq. 3.) However, the main sideband of Mf has a much larger $R$ value of 0.414 (Cartwright and Tayler, 1971; Cartwright and Edden, 1973), from which Eq. (A3) gives a time dependence of $0.382 \cos (n t)$. As can be seen from Eq. (4), Doodson ignored the complication of the denominator and took $R \cos (n t)$ to also apply for Mf.

The first and third terms provide the time-independent part of $f$ for which Doodson took the time-average value of the third term. When $R$ is very small, the sum of the first and third terms can be approximated by

$$
\left(1+\frac{R^{2}}{2}\right)-\left(\frac{R^{2}}{4}\right)=1+\frac{R^{2}}{4},
$$

from which one obtains 1.0004 for M2 (Doodson, 1928). When $R$ is larger, we would have

$$
\sqrt{1+R^{2}}-\frac{R^{2}}{4\left(1+R^{2}\right)^{\frac{3}{2}}},
$$

which gives a value for Mf of 1.0485 given that $R=0.414$. However, once again, Doodson appears to have assumed the small $R$ approximation of Eq. (A4), giving the 1.043 in Eq. (4).

From Eqs. (2) and (A1), we can express the nodal factor for phase lag as

$$
u=\tan ^{-1}\left(\frac{R \sin (n t)}{1+R \cos (n t)}\right),
$$

and from the Maclaurin series $\tan ^{-1} x=x-\frac{x^{3}}{3}+\frac{x^{5}}{5}$, etc. for $-1<x<1$, this gives $u=R \sin (n t)$ if the denominator is taken to be 1.0 for small values of $R$. Once again, this is clearly an acceptable approximation for M2. However, Doodson also used this approximation for Mf, resulting in the $u=0.414 \sin (n t)$ radians or $23.7^{\circ} \sin (n t)=-23.7^{\circ} \sin (N)$ as in Eq. (4).

As a test of whether these approximations by Doodson matter, Fig. 9a and $\mathrm{b}$ show the values of $f$ and $u$ that one obtains for Mf by calculating them rigorously using Eqs. (A2) and (A6), or by using Doodson's formulae. It can be seen that Doodson's values of $f$ and $u$ are good approximations, with standard deviations of the differences between the red and blue curves of 0.03 and $3.6^{\circ}$, respectively. Therefore, they can be adopted reliably for analysis of generally noisy tide gauge or BPR data. However, in other tidal applications, they may not be adequate. For example, Ray and Egbert (2012) made a study of fortnightly variations in Earth rotation. When the nodal sidebands of Mf were treated rigorously, and additional double-nodal and double-perigean sidebands were included (i.e. sidebands with angular speeds which differ from that of the main line by the angular speeds of $2 N^{\prime}$ and $2 p$, respectively, where $p$ is the angle of lunar perigee), then improvements were obtained over the Doodson descriptions of $f$ and $u$ we have used here, which in turn improved upon their interpretation of high-precision length of day information.

As mentioned above, the formulae for $f$ and $u$ presented in Doodson (1928) and Doodson and Warburg (1941) are more complicated than the simplified ones discussed here. For example, his values for Mf include the double-nodal terms considered by Ray and Egbert (2012) (but not the doubleperigean ones), and these more complete expressions will have been included in most tidal analysis and prediction software packages. 
Finally, we can refer to Mm which has two nodal sidebands with amplitudes that are the same to within $1 \%$, and that have opposite sign to that of the $\mathrm{Mm}$ central line in the harmonic expansion of the tidal potential (Cartwright and Tayler, 1971; Cartwright and Edden, 1973). The total tide can then be expressed as

$$
\begin{aligned}
\cos (w t) & -R \cos ((w+n) t)-R \cos ((w-n) t) \\
& =[1-2 R \cos (n t)] \cos (w t) .
\end{aligned}
$$

It is straightforward to see that in this case when $R=0.065$ that:

$f=1-0.130 \cos (N)$ and $u=0.0$

as shown in Eq. (8).

A more complicated discussion of $\mathrm{Mm}$ would include its other sidebands. Mm has Doodson number 0, 1, 0,-1, 0, 0. Its main double-perigean sideband $0,1,0,1,0,0$ (i.e. differing by $2 p$ from the main line) has an amplitude $\sim 5 \%$ of $\mathrm{Mm}$ itself (as does the double-perigean sideband of Mf), while there is a component $0,1,0,1,1,0$ (i.e. differing by $2 p+N^{\prime}$ from the main line). There is even a third-degree singleperigean component $0,1,0,0,0,0$ (i.e. differing by $p$ from the main line). The overall nodal factors $f$ and $u$ can then be obtained via

$$
\begin{aligned}
f \cos (u) & =1.0-0.130 \cos (N)-0.0535 \cos (2 p) \\
& -0.0216 \cos (2 p-N)-0.0551 \sin (p) \\
f \sin (u) & =-0.0535 \sin (2 p)-0.0216 \sin (2 p-N) \\
& +0.0551 \cos (p),
\end{aligned}
$$

where the amplitudes of each term are taken from Cartwright and Tayler (1971) and that of the third-degree term is evaluated at $58^{\circ} \mathrm{S}$. Figure 10 indicates the simple nodal components of $f$ and $u$ as described by Eq. (8) (or Eq. A8) by thin black and blue lines, respectively. The overall values after combining all components in Eq. (A9) are shown by the thick lines. (This would presuppose that both the secondand third-degree long-period tides have a near-equilibrium behaviour. The overall values if one were to include only second-degree components are shown in Fig. S4.) Equation (8) can be seen to be a good approximation of the overall $f$ and $u$ in spite of the other sidebands. 
Supplement. The supplement related to this article is available online at: https://doi.org/10.5194/os-14-711-2018-supplement.

Author contributions. AH was responsible for the quality control of most of the BPR records. PLW made the analyses of nodal variations in the long-period tides. Both were responsible for the text.

Competing interests. The authors declare that they have no conflict of interest.

Special issue statement. This article is part of the special issue "Developments in the science and history of tides (OS/ACP/HGSS/NPG/SE inter-journal SI)". It is not associated with a conference.

Acknowledgements. The programme of the Drake Passage bottom pressure measurements was led by scientists from the National Oceanography Centre including Ian Vassie, Mike Meredith, Chris Hughes and Miguel Ángel Morales Maqueda. The bottom pressure recorders were designed, constructed and deployed by Bob Spencer, Peter Foden, Jeff Pugh, Steve Mack, Geoff Hargreaves and others. The help of the British Antarctic Survey with the deployments is much appreciated. Data sets were processed by David Blackman, Philip Axe and Angela Hibbert, and may be obtained from the websites mentioned in Sect. 2 or from the authors of this paper. The NERC "Weighing the Ocean" project (grant no. NEW344022) was led by Mark Tamisiea and Chris Hughes. Loren Carrère is thanked for advice on the FES2014 ocean tide model which is distributed by AVISO (https://www.aviso.altimetry.fr/, last access: 1 June 2018). The DAC data sets may also be obtained from AVISO. NEMO ocean model data and advice on this study were provided by Chris Hughes. We are grateful to Richard Ray and Simon Williams for comments on aspects of this work, and to Xiangbo Feng and a second reviewer for their detailed remarks. Part of this work was funded by UK Natural Environment Research Council National Capability funding. Some figures were generated using the Generic Mapping Tools (Wessel and Smith, 1998).

Edited by: Mattias Green

Reviewed by: Xiangbo Feng and one anonymous referee

\section{References}

Amin, M.: On perturbations of harmonic constants in the Thames Estuary, Geophys. J. Roy. Astr. Soc., 73, 587-603, https://doi.org/10.1111/j.1365-246X.1983.tb03334.x, 1983.

Amin, M.: Temporal variations of tides on the west coast of Great Britain, Geophys. J. Roy. Astr. Soc., 82, 279-299, https://doi.org/10.1111/j.1365-246X.1985.tb05138.x, 1985.

Amin, M.: Changing mean sea level and tidal constants on the west coast of Australia, Mar. Freshwater Res., 44, 911-925, https://doi.org/10.1071/MF9930911, 1993.
Bell, C., Vassie, J. M., and Woodworth, P. L.: The Tidal Analysis Software Kit (TASK Package), TASK-2000 version dated December 1998, National Oceanography Centre, Liverpool, 1996.

Carrère, L. and Lyard, F.: Modeling the barotropic response of the global ocean to atmospheric wind and pressure forcing comparisons with observations, Geophys. Res. Lett., 30, 1275, https://doi.org/10.1029/2002GL016473, 2003.

Cartwright, D. E.: Tides: a scientific history, Cambridge University Press, Cambridge, 292 pp., 1999.

Cartwright, D. E. and Edden, A. C.: Corrected tables of tidal harmonics, Geophys. J. Roy. Astr. Soc., 33, 253-264, https://doi.org/10.1111/j.1365-246X.1973.tb03420.x, 1973.

Cartwright, D. E. and Tayler, R. J.: New computations of the tidegenerating potential, Geophys. J. Roy. Astr. Soc., 23, 45-74, https://doi.org/10.1111/j.1365-246X.1971.tb01803.x, 1971.

Cartwright, D. E., Spencer, R., and Vassie, J. M.: Pressure variations on the Atlantic equator, J. Geophys. Res., 92, 725-741, https://doi.org/10.1029/JC092iC01p00725, 1987.

Cartwright, D. E., Spencer, R., Vassie, J. M., and Woodworth, P. L.: The tides of the Atlantic Ocean, $60^{\circ} \mathrm{N}$ to $30^{\circ} \mathrm{S}$, Philos. T. Roy. Soc. Lond. A, 324, 513-563, https://doi.org/10.1098/rsta.1988.0037, 1988.

Crawford, W. R.: Analysis of fortnightly and monthly tides, Int. Hydrogr. Rev., LIX, 131-141, 1982.

Doodson, A. T.: The harmonic development of the tide-generating potential, Philos. T. Roy. Soc. Lond. A, 100, 305-329, https://doi.org/10.1098/rspa.1921.0088, 1921.

Doodson, A. T.: VI. The analysis of tidal observations, Philos. T. Roy. Soc. Lond. A, 227, 223-279, https://doi.org/10.1098/rsta.1928.0006, 1928.

Doodson, A. T. and Warburg, H. D.: Admiralty Manual of Tides, His Majesty's Stationery Office, London, 270 pp., 1941.

Egbert, G. D. and Ray, R. D.: Deviation of long-period tides from equilibrium: kinematics and geostrophy, J. Phys. Oceanogr., $\quad 33, \quad 822-839, \quad$ https://doi.org/10.1175/15200485(2003)33<822:DOLTFE >2.0.CO;2, 2003.

Feng, X., Tsimplis, M. N., and Woodworth, P. L.: Nodal variations and long-term changes in the main tides on the coasts of China, J. Geophys. Res.-Oceans, 120, 1215-1232, https://doi.org/10.1002/2014JC010312, 2015.

FES2014: Description of the FES2014 ocean tide model, available at: https://www.aviso.altimetry.fr/en/data/products/ auxiliary-products/global-tide-fes/description-fes2014.html, last access: January 2018.

Foreman, M. G. G. and Neufeld, E. T.: Harmonic tidal analyses of long series, Int. Hydrogr. Rev., LXVIII, 85-108, 1991.

Gross, R. S.: An improved empirical model for the effect of longperiod ocean tides on polar motion, J. Geod., 83, 635-644, https://doi.org/10.1007/s00190-008-0277-y, 2009.

Hibbert, A., Leach, H., Woodworth, P. L., Hughes, C. W., and Roussenov, V. M.: Quasi-biennial modulation of the Southern Ocean coherent mode, Q. J. Roy. Meteorol. Soc., 136, 755-768, https://doi.org/10.1002/qj.581, 2010.

Hughes, C. W., Woodworth, P. L., Meredith, M. P., Stepanov, V., Whitworth, T., and Pyne, A. R.: Coherence of Antarctic sea levels, Southern Hemisphere Annular Mode, and flow through Drake Passage, Geophys. Res. Lett., 30, 1464, https://doi.org/10.1029/2003GL017240, 2003. 
Hughes, C. W., Williams, J., Blaker, A., Coward, A., and Stepanov, V.: A window on the deep ocean: The special value of ocean bottom pressure for monitoring the largescale, deep-ocean circulation, Prog. Oceanogr., 161, 19-46, https://doi.org/10.1016/j.pocean.2018.01.011, 2018.

Kantha, L. H., Stewart, J. S., and Desai, S. D.: Long-period lunar fortnightly and monthly ocean tides, J. Geophys. Res., 103, 12639-12647, https://doi.org/10.1029/98JC00888, 1998.

$\mathrm{Ku}$, L. F., Greenberg, D. A., Garrett, C. J. R., and Dobson, F. W.: Nodal modulation of the lunar semidiurnal tide in the Bay of Fundy and Gulf of Maine, Science, 230, 69-71, https://doi.org/10.1126/science.230.4721.69, 1985.

Lyard, L., Lefevre, F., Letellier, T., and Francis, O.: Modelling the global ocean tides: modern insights from FES2004, Ocean Dynam., 56, 394-415, https://doi.org/10.1007/s10236-006-0086-x, 2006.

Mathers, E. L. and Woodworth, P. L.: Departures from the local inverse barometer model observed in altimeter and tide gauge data and in a global barotropic numerical model, J. Geophys. Res., 106, 6957-6972, https://doi.org/10.1029/2000JC000241, 2001.

Matthews, A. J. and Meredith, M. P.: Variability of the Antarctic circumpolar transport and the Southern Annular Mode associated with the Madden-Julian Oscillation, Geophys. Res. Lett., 31, L24312, https://doi.org/10.1029/2004GL021666, 2004.

Meredith, M. P., Woodworth, P. L., Hughes, C. W., and Stepanov, V.: Changes in the ocean transport through Drake Passage during the 1980s and 1990s, forced by changes in the Southern Annular Mode, Geophys. Res. Lett., 31, L21305, https://doi.org/10.1029/2004GL021169, 2004.

Meredith, M. P., Woodworth, P. L., Chereskin, T. K., Marshall, D. P., Allison, L. C., Bigg, G. R., Donohue, K., Heywood, K. J., Hughes, C. W., Hibbert, A., McHogg, A. C. Johnson, H. L., King, B. A., Leach, H., Lenn, Y.-D., Morales Maqueda, M. A., Munday, D. R., Naveira Garabato, A. C., Provost, C., and Sprintall, J.: Sustained monitoring of the Southern Ocean at Drake Passage: past achievements and future priorities, Rev. Geophys., 49, RG4005, https://doi.org/10.1029/2010RG000348, 2011.

Miller, A. J., Luther, D. S., and Hendershott, M. C.: The fortnightly and monthly tides: resonant Rossby waves or nearly equilibrium gravity waves? J. Phys. Oceanogr., 23, 879-897, https://doi.org/10.1175/15200485(1993)023<0879:TFAMTR>2.0.CO;2, 1993.

Müller, M.: Rapid change in semi-diurnal tides in the North Atlantic since 1980, Geophys. Res. Lett., 38, L11602, https://doi.org/10.1029/2011GL047312, 2011.

Munk, W. H. and Cartwright, D. E.: Tidal spectroscopy and prediction, Philos. T. Roy. Soc. Lond. A, 259, 533-581, https://doi.org/10.1098/rsta.1966.0024, 1966.

Polster, A., Fabian, M., and Villinger, H.: Effective resolution and drift of Paroscientific pressure sensors derived from long-term seafloor measurements, Geochem. Geophy. Geosy., 10, Q08008, https://doi.org/10.1029/2009GC002532, 2009.

Proudman, J.: The condition that a long-period tide shall follow the equilibrium law, Geophys. J. Roy. Astr. Soc., 3, 244-249, https://doi.org/10.1111/j.1365-246X.1960.tb00392.x, 1960.

Pugh, D. T. and Woodworth, P. L.: Sea-level science: Understanding tides, surges, tsunamis and mean sea-level changes, Cambridge University Press, Cambridge, 408 pp., 2014.
Rabinovich, A. B., Woodworth, P. L., and Titov, V. V.: Deep-sea observations and modeling of the 2004 Sumatra tsunami in Drake Passage, Geophys. Res. Lett., 38, L16604, https://doi.org/10.1029/2011GL048305, 2011.

Ray, R. D.: Secular changes of the M2 tide in the Gulf of Maine, Cont. Shelf Res., 26, 422-427, https://doi.org/10.1016/j.csr.2005.12.005, 2006.

Ray, R. D.: Precise comparisons of bottom-pressure and altimetric ocean tides, J. Geophys. Res.-Oceans, 118, 4570-4584, https://doi.org/10.1002/jgrc.20336, 2013.

Ray, R. D. and Egbert, G. D.: Fortnightly Earth rotation, ocean tides and mantle anelasticity, Geophys. J. Int., 189, 400-413, https://doi.org/10.1111/j.1365-246X.2012.05351.x, 2012.

Ray, R. D. and Erofeeva, S. Y.: Long-period tidal variations in the length of day, J. Geophys. Res.-Solid Ea., 119, 1498-1509, https://doi.org/10.1002/2013JB010830, 2014.

Schwiderski, E. W.: Global ocean tides. Part X. The fortnightly lunar tide (Mf), in: Atlas of Tidal Charts and Maps, Report TR 82151, Naval Surface Weapons Center, Dahlgren, VA, 1982.

Sheen, K. L., Naveira Garabato, A. C., Brearley, J. A., Meredith, M. P., Polzin, K. L., Smeed, D. A., Forryan, A., King, B. A., Sallée, J.-B., St. Laurent, L., Thurnherr, A. M., Toole, J. M., Waterman, S. N., and Watson, A. J.: Eddy-induced variability in Southern Ocean abyssal mixing on climatic timescales, Nat. Geosci., 7, 577-582, https://doi.org/10.1038/NGEO2200, 2014.

Spencer, R. and Vassie, J. M.: The evolution of deep ocean pressure measurements in the U.K., Prog. Oceanogr., 40, 423-435, https://doi.org/10.1016/S0079-6611(98)00011-1, 1997.

Trupin, A. and Wahr, J.: Spectroscopic analysis of global tide gauge sea level data, Geophys. J. Int., 100, 441-453, https://doi.org/10.1111/j.1365-246X.1990.tb00697.x, 1990.

Watts, D. R. and Kontoyiannis, H.: Deep-ocean bottom pressure measurement: Drift removal and performance, J. Atmos. Ocean. Tech., 7, 296-306, https://doi.org/10.1175/15200426(1990)007<0296:DOBPMD>2.0.CO;2, 1990.

Wessel, P. and Smith, W. H. F.: New, improved version of generic mapping tools released, EOS Trans. Am. Geophys. Un., 79, 579, 1998.

Williams, S. D. P.: The effect of coloured noise on the uncertainties of rates estimated from geodetic time series, J. Geod., 76, 483494, https://doi.org/10.1007/s00190-002-0283-4, 2003.

Woodworth, P. L.: A survey of recent changes in the main components of the ocean tide, Cont. Shelf Res., 30, 1680-1691, https://doi.org/10.1016/j.csr.2010.07.002, 2010.

Woodworth, P. L.: A note on the nodal tide in sea level records, J. Coast. Res., 28, 316-323, https://doi.org/10.2112/JCOASTRESD-11A-00023.1, 2012.

Woodworth, P. L., Shaw, S. M., and Blackman, D. B.: Secular trends in mean tidal range around the British Isles and along the adjacent European coastline, Geophys. J. Int., 104, 593-610, https://doi.org/10.1111/j.1365-246X.1991.tb05704.x, 1991.

Woodworth, P. L., Vassie, J. M., Hughes, C. W., and Meredith, M. P.: A test of the ability of TOPEX/POSEIDON to monitor flows through the Drake Passage, J. Geophys. Res., 101, 11935-11947, https://doi.org/10.1029/96JC00350, 1996.

Woodworth, P. L., Le Provost, C., Rickards, L. J., Mitchum, G. T., and Merrifield, M.: A review of sea-level research from tide gauges during the World Ocean Circulation Experiment, Oceanogr. Mar. Biol., 40, 1-35, 2002. 
Woodworth, P. L., Hughes, C. W., Blackman, D. L., Stepanov, V. N., Holgate, S. J., Foden, P. R., Pugh, J. P., Mack, S., Hargreaves, G. W., Meredith, M. P., Milinevsky, G., and Fierro Contreras, J. J.: Antarctic peninsula sea levels: a real time system for monitoring Drake Passage transport, Antarct. Sci., 18, 429-436, https://doi.org/10.1017/S0954102006000472, 2006.
Woodworth, P. L., Hunter, J. R. Marcos, M., Caldwell, P., Menéndez, M., and Haigh, I.: Towards a global higherfrequency sea level data set, Geosci. Data J., 3, 50-59, https://doi.org/10.1002/gdj3.42, 2017.

Wunsch, C.: The long-period tides, Rev. Geophys. Space Phys., 5, 447-475, https://doi.org/10.1029/RG005i004p00447, 1967.

Wunsch, C., Haidvogel, D. B., Iskandarani, M., and Hughes, R.: Dynamics of the long-period tides, Prog. Oceanogr., 40, 81-108, https://doi.org/10.1016/S0079-6611(97)00024-4, 1997. 